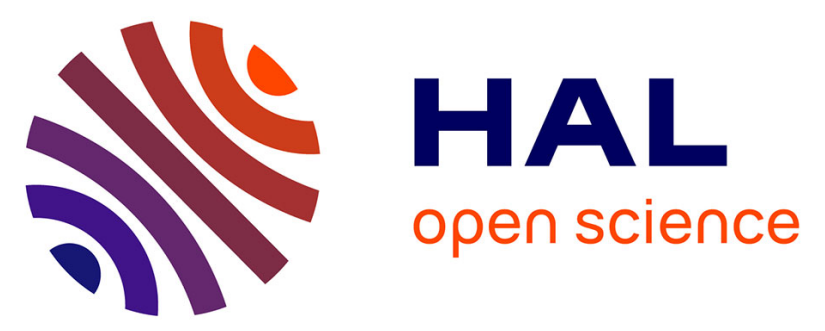

\title{
The conversion of glutamate by glutamine synthase in neocortical astrocytes from juvenile rat is important to limit glutamate spillover and peri/extrasynaptic activation of NMDA receptors
}

Yosra Trabelsi, Mohamed Amri, Hélène Becq, Florence Molinari, Laurent Aniksztejn

\section{To cite this version:}

Yosra Trabelsi, Mohamed Amri, Hélène Becq, Florence Molinari, Laurent Aniksztejn. The conversion of glutamate by glutamine synthase in neocortical astrocytes from juvenile rat is important to limit glutamate spillover and peri/extrasynaptic activation of NMDA receptors. Glia, 2017, 65 (2), pp.401415. 10.1002/glia.23099 . hal-01962551

\section{HAL Id: hal-01962551 \\ https://hal-amu.archives-ouvertes.fr/hal-01962551}

Submitted on 20 Dec 2018

HAL is a multi-disciplinary open access archive for the deposit and dissemination of scientific research documents, whether they are published or not. The documents may come from teaching and research institutions in France or abroad, or from public or private research centers.
L'archive ouverte pluridisciplinaire HAL, est destinée au dépôt et à la diffusion de documents scientifiques de niveau recherche, publiés ou non, émanant des établissements d'enseignement et de recherche français ou étrangers, des laboratoires publics ou privés. 


\title{
The Conversion of Glutamate by Glutamine Synthase in Neocortical Astrocytes from Juvenile Rat Is Important to Limit Glutamate Spillover and Peri/Extrasynaptic Activation of NMDA Receptors
}

\author{
Yosra Trabelsi, ${ }^{1,2}$ Mohamed Amri, ${ }^{3}$ Hélène Becq, ${ }^{1,2}$ Florence Molinari, ${ }^{1,2}$ and \\ Laurent Aniksztejn ${ }^{1,2}$
}

Glutamate transporters (EAATs) are important to maintain spatial and temporal specificity of synaptic transmission. Their efficiency to uptake and transport glutamate into the intracellular space depends on several parameters including the intracellular concentrations of $\mathrm{Na}^{+}$and glutamate, the elevations of which may slow down the cycling rate of EAATs. In astrocytes, glutamate is maintained at low concentration due to the presence of specific enzymes such as glutamine synthase (GS). GS inhibition results in cytosolic accumulation of glutamate suggesting that the conversion of glutamate by GS is important for EAATs operation. Here we recorded astrocytes from juvenile rat neocortical slices and analyzed the consequences of elevated intracellular glutamate concentrations and of GS inhibition on the time course of synaptically evoked transporter current (STC). In slices from rats treated with methionine sulfoximine (MSO), a GS inhibitor, STC evoked by short burst of high frequency stimulation (HFS; $100 \mathrm{~Hz}$ for $100 \mathrm{~ms}$ ) but not by low frequency stimulation (LFS; $0.1 \mathrm{~Hz}$ ) was twice slower than STC evoked from saline injected rats. Same results were obtained for astrocytes recorded with pipette containing 3-10 mM glutamate and compared with cells recorded with 0 or1 $\mathrm{mM}$ glutamate in the patch pipette. We also showed that HFS elicited significantly larger NMDAR-excitatory postsynaptic currents (EPSCs) with a stronger peri/extrasynaptic component in pyramidal cells from MSO-treated compared with saline treated rats. Taken together our data demonstrate that the conversion of glutamate by GS is fundamental to ensure an efficient clearance of glutamate by EAATs and to prevent glutamate spillover.

GLIA 2016;00:000-000 Key words: glutamine synthase, glutamate transporters, astrocytes, NMDA receptors, glutamate spillover, neocortex, methionine sulfoximine

\section{Introduction}

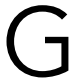
lutamate is the main excitatory transmitter in the CNS and plays major roles in brain development and complex physiological functions, including neurogenesis, cell migration, synapse formation, learning, memory, plasticity. Dysregulation of glutamate metabolism or homeostasis has been involved in severe pathologies such as neurodegenerative diseases (amyotrophic lateral sclerosis, Alzheimer's disease, ...) and epilepsies (Danbolt, 2001; Maragakis and Rothstein,
2004; Vandenberg and Ryan, 2013). The influence exerted by glutamate in the brain is determined by the spatiotemporal distribution of its concentration in the extracellular space $\left([\mathrm{Glu}]_{\mathrm{o}}\right)$. This parameter influences the number and subtype of glutamate receptors activated by the transmitter and so the amplitude and the duration of the synaptic signal. Regulation of $[\mathrm{Glu}]_{\mathrm{o}}$ is strongly controlled by excitatory amino acid transporters (EAATs). EAATs are located at the cell surface of neurons and glial cells and they bind and transport glutamate

View this article online at wileyonlinelibrary.com. DOI: 10.1002/glia.23099

Published online Month 00, 2016 in Wiley Online Library (wileyonlinelibrary.com). Received July 1, 2016, Accepted for publication Oct 26, 2016.

Address correspondence to: Laurent Aniksztejn, INMED-INSERM U901, Parc Scientifique de Luminy, 13273 Marseille cedex 09, France.

E-mail: laurent.aniksztejn@inserm.fr

From the ${ }^{1}$ Institut de Neurobiologie de la Méditerranée (INMED), Aix-Marseille Université, Marseille 13009, France; ${ }^{2}$ INSERM, UMR_S 901, Marseille 13009, France;

${ }^{3}$ Laboratoire de Neurophysiologie Fonctionnelle et Pathologies, Tunis UR11ES09, Tunisie 
from extracellular to intracellular spaces (Cavelier et al., 2005; Danbolt, 2001; Huang and Bergles, 2004; Grewer and Rauen, 2005; Tzingounis and Wadiche, 2007; Vandenberg and Ryan, 2013). Through these actions, EAATs preserve the responsiveness of glutamate receptors and prevent against glutamate-induced excitotoxicity. EAATs also help to maintain spatio-temporal specificity of synaptic transmission by preventing against the diffusion of glutamate release out of active synapses. Moreover, EAATs contribute to maintain a low ambient concentration of glutamate (Arnth-Jensen et al., 2002; Asztely et al., 1997; Bergles et al., 1999; Diamond, 2001; Herman and Jahr, 2007; Huang and Bergles, 2004; Marcaggi and Attwell, 2004; Takahashi et al. 1997; Tzingounis and Wadiche, 2007). Five subtypes of EAATs have been identified so far: EAAT1/GLAST (humans/rodents) and EAAT2/GLT1 are expressed in glial cells; in the cortex GLT1 is also detected in neurons in presynaptic terminals. The three others (EAAT3/EAAC1; EAAT4; EAAT5) are expressed in neurons (Danbolt, 2001; Melone et al., 2009). In the cortex, neuronal glutamate transporters act primarily as a glutamate buffering system but the transport of glutamate is mainly achieved by glial cells (Diamond, 2001; Tzingounis and Wadiche, 2007; Scimemi et al., 2009). Indeed, glial cells are responsible for the absorption and metabolism of the major part of glutamate in the brain (Danbolt, 2001). This is due to: (i) high glutamate transporters expression on glial cells; (ii) their very hyperpolarized resting membrane potential and low input resistance that prevent against strong depolarization. Altogether this provides favorable conditions for the translocation of glutamate into the cells (Barbour et al., 1991; Brew and Attwell, 1987; Huang and Bergles, 2004). Another important parameter that is likely to play an important role is the intracellular glutamate concentration, which in the cytoplasm of astrocytes, is 10- to 20-fold lower than in neurons (Nedergaard et al., 2002; Zhou et al., 2014). Different studies have demonstrated that intracellular glutamate elevation, together with $\mathrm{Na}^{+}$intracellular elevation, decreased glutamate transporters current evoked by exogenous application of glutamate, and affected the net number of molecules of glutamate transported (Barbour et al., 1991; Otis and Jahr, 1998). The low intracellular glutamate concentration in astrocytes is due to several enzymes located in the cytosol and the mitochondria that rapidly catabolize the amino acid into different metabolites. In the cytosol the most important one is glutamine synthase (GS). This enzyme, which is specifically expressed by astrocytes, converts glutamate that has been taken up by glutamate transporters into glutamine in the presence of ATP and $\mathrm{NH}_{3}$. Reduced expression or inactivation of GS is associated with seizures in both human and rodents (Cloix et al., 2010; Eid et al., 2004, 2008, 2013; Häberle et al., 2005, 2011). It was proposed that GS deficiency may impact on glutamate transporters operation since its inhibition leads to an accumulation of glutamate in astrocytes (Coulter and Eid, 2012; Eid et al., 2013; Laake et al., 1995; Perez et al., 2012). Interestingly, we and others reported that a deficit in glutamate transport caused seizures in vivo and epileptical like activities in vitro in both hippocampus and neocortex suggesting a possible link between GS and EAATs (Cattani et al., 2007; Demarque et al., 2004; Milh et al., 2007; Molinari et al., 2012; Sepkuty et al., 2002; Tanaka et al., 1997). However, evidences that GS inactivation affected glutamate transporters efficiency have not yet been provided. In the present study, we investigated this issue by measuring the time course of synaptically activated transporter current (STC) in juvenile rat neocortical astrocytes and showed that inactivation of GS slowed the decay time constant of STC evoked by short burst of high frequency stimulation and facilitated activation of peri/extrasynaptic NMDA receptors.

\section{Materials and Methods Slices Preparation}

Experiments were performed on astrocytes and pyramidal neurons located in layer IV/V of neocortical slices obtained from postnatal day 13-16 old Wistar rats (males/females) (INMED animal facilities).

Wistar rats were decapitated under chloral hydrate anesthesia $(20-40 \mathrm{mg} / \mathrm{kg})$. Brains were rapidly removed and placed in oxygenated ice-cooled artificial cerebrospinal fluid (ACSF) with the following composition (in $\mathrm{mM}$ ): $126 \mathrm{NaCl}, 3.5 \mathrm{KCl}, 2 \mathrm{CaCl}_{2}, 1.3$ $\mathrm{MgCl}_{2}, 25 \mathrm{NaHCO}_{3}, 1.2 \mathrm{NaHPO}_{4}$, and 10 glucose $\left(95 \% \mathrm{O}_{2}-5 \%\right.$ $\mathrm{CO}_{2}, \mathrm{pH}$ 7.4). Coronal neocortical slices (400 $\mu \mathrm{m}$ thick) were obtained with a vibratome (Leica VT1200S). Following sectioning, slices were incubated in oxygenated ACSF containing $1 \mu M$ sulforhodamine 101 (SR-101) for $20 \mathrm{~min}$ at $34^{\circ} \mathrm{C}$ followed by $10 \mathrm{~min}$ incubation in ACSF for $10 \mathrm{~min}$ at $34^{\circ} \mathrm{C}$. This procedure described by Kafitz et al. (2008) allows identifying astrocytes in slices for electrophysiological recordings. Slices were kept in ACSF at room temperature at least $1 \mathrm{~h}$ before used. Individual slices were then transferred to the recording chamber where they were fully submerged and superfused with $\mathrm{ACSF}$ at $34-35^{\circ} \mathrm{C}$ at a rate of $4.5-$ $5 \mathrm{~mL} / \mathrm{min}$.

\section{Electrophysiology}

Astrocytes were recorded under visual control with a Zeiss Axioscope microscope using whole cell configuration. Patch electrodes were made from borosilicate glass capillaries (GC150F-15, Clark Electromedical Instruments). They had a resistance of 4-6 M Ohm and were filled with a solution of the following composition (in $\mathrm{m} M$ ): 130 KGlu, 10 EGTA, 10 HEPES-Na, $3 \mathrm{Mg}^{2+}$-ATP, $0.3 \mathrm{Na}^{+}$-GTP, 10 phosphocreatinine. In some experiments L-glutamate at 1,3 , or $10 \mathrm{~m} M$ was added to the pipette solution.

Astrocytes were held at $-80 \mathrm{mV}$ and transporter currents were evoked by electrical stimulation (synaptically evoked transporter 
current, STC) using a bipolar nickel-chrome electrode positioned near the recorded astrocyte. The pipette solution used to record astrocytes and the holding potential allow minimizing the uncoupled EAAT anion current to STC. The stimulation protocol is close to that described by Diamond and Jahr (2000) and consisted to evoke STC by $5-10$ stimuli at $0.1 \mathrm{~Hz}(60 \mu$ s duration, the intensity adjusted to evoke a response of 150-250 pA) corresponding to low frequency stimulation (LFS) followed by 10 stimuli at $100 \mathrm{~Hz}$ and $30 \mathrm{~s}$ latter by 11 stimuli at $100 \mathrm{~Hz}$ corresponding to high frequency stimulations (HFS). Each series of stimulation $(0.1 \mathrm{~Hz}$ followed by $100 \mathrm{~Hz}$ ) were repeated maximum 10 times when possible with an interval of $30 \mathrm{~s}$. These series were numbered as serie \#1, serie \#2,... serie\#10. STC elicited by high frequency stimulation (HFS) was extracted after subtracting transporter current evoked by 11 stimuli from that evoked by 10 stimuli. The response is named $S T C_{H F S}$

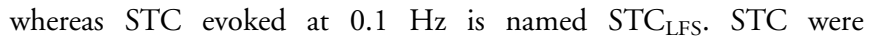
recorded in continuous presence of $\mathrm{D}-(-)-2$-amino-5-phosphonopentaoic acid (D-AP5, $50 \mu M$ ); 2,3-dioxo-6-nitro-1,2,3,4-tetrahydrobenzo[f] quinoxaline-7-sulfonamide (NBQX, $20 \mu M$ ); 6-imino-3-(4methoxyphenyl)-1(6H)-pyridazinebutanoic acid hydrobromide (SR95531, Gabazine, $5 \mu M$ ); (2S)-2-amino-2-[(1S,2S)-2-carboxycycloprop-1-yl]-3-(xanth-9-yl) propanoic acid (LY341495, $1 \mu M$ ); (2S) -3-[[(1S)-1-(3,4-dichlorophenyl)ethyl] amino-2-hydroxypropyl] (phenylmethyl)phosphinicacid hydrochloride (CGP55845A, $10 \mu M)$; nipecotic acid $(1 \mathrm{~m} M), \mathrm{BaCl}_{2}(200 \mu M)$. These drugs were used to block ionotropic and metabotropic GABA and glutamate receptors, GABA transporters, and Kir channels. All these drugs were purchased from Tocris Bioscience.

Neurons were recorded in whole cell configuration with a patch electrode filled with a solution of the following composition (in $\mathrm{m} M$ ): 130 CsGlu; 10 HEPES, 10 BAPTA, $3 \mathrm{Mg}^{2+}$-ATP, 0.3 $\mathrm{Na}^{+}$-GTP, 10 phosphocreatinine. BAPTA was used to prevent synaptic plasticity (long-term potentiation/depression). NMDAR-and AMPAR-mediated excitatory postsynaptic currents were evoked either at $0.1 \mathrm{~Hz}\left(\right.$ NMDAR-EPSC $_{\mathrm{LFS}}$ or AMPAR-EPSC $\mathrm{LFS}_{\mathrm{LS}}$ ) or by 10 pulses at $100 \mathrm{~Hz}$ (NMDAR-EPSC $\mathrm{HFS}_{\mathrm{HF}}$ or AMPAR-EPSC $\mathrm{HFS}_{\mathrm{HF}}$ ). EPSCs were recorded in continuous presence of Gabazine $(5 \mu M)$, LY341495 $(1 \mu M)$ and supplemented with NBQX $(20 \mu M)$ when NMDAR-EPSC were recorded or D-APV $(50 \mu M)$ when AMPAREPSC were recorded. The extracellular solution contained also high concentrations of $\mathrm{Mg}^{2+}$ and $\mathrm{Ca}^{2+}$ (6 and $4 \mathrm{~m} M$, respectively) to block polysynaptic activity.

All measurements were filtered at $3 \mathrm{kHz}$ using an EPC-9 amplifier (HEKA Electronik), electrophysiological data were digitized $(1-2 \mathrm{kHz})$ with a Digidata (Axon Instruments) interface card to a personal computer.

To measure the decay time constant, current traces were fitted with a single or a double exponential function of the following form: $y=\operatorname{Afastexp}(\tau / \tau$ fast $)+\operatorname{Aslowexp}(\tau / \tau$ slow) (where Afast and Aslow are the fractions of the fast and slow component of the current and $\tau$ fast and $\tau$ slow are the respective fast and slow time constant). The time constant representing the weighted average of the fast and slow components of current decay was calculated with the following equation: $\tau=(\tau$ fastAfast $+\tau$ slowAslow $) /($ Afast + Aslow $)$. Currents were analyzed using Origin 8.0 software.
Access resistance was measured from the peak of the current transient elicited by a $2 \mathrm{mV}$ test pulse of $50 \mathrm{~ms}$ duration and applied before each EPSC $_{\mathrm{LFS}}$ or $\mathrm{STC}_{\mathrm{LFS}}$ and was not compensated. The access resistance ranged between 20 and $30 \mathrm{M}$ Ohm. Experiments were stopped when the resistance was increased by more than $20 \%$. Membrane potentials of astrocytes and neurons were not corrected for liquid junction potential.

\section{Injection of MSO}

L-methionine-DL-sulfoximine (MSO, Sigma Aldrich France) was dissolved in $\mathrm{NaCl}(0.09 \%)$ and administered intraperitoneally in a dose of $170 \mathrm{mg} / \mathrm{kg}$ as previously described (Sellinger et al., 1968) the day before electrophysiological recordings. Sham animals were injected only with $\mathrm{NaCl} 0.09 \%$.

\section{HPLC Analysis for Amino Acids Levels}

Twenty-four hours after the injection of $\mathrm{MSO}$ or $\mathrm{NaCl}$, the brain was removed and coronal cortical slices were obtained as described earlier. After incubation for $1 \mathrm{~h}$ in ACSF at room temperature, slices were freeze-dried, dialyzed with lysis buffer $(50 \mathrm{~m} M$ TrisHCl, $1 \mathrm{~m} M$ EDTA, $1 \%$ Triton; $10 \mu \mathrm{L} / 1 \mathrm{mg}$ of tissue), sonicated and centrifuged $\left(5 \mathrm{~min}, 15,000 \mathrm{~g}\right.$ at $4^{\circ} \mathrm{C}$ ). Supernatants were deproteinized with perchloric acid $(0.5 \mathrm{M}, \mathrm{v} / \mathrm{v})$ for $10 \mathrm{~min}$ at $4^{\circ} \mathrm{C}$ and precipitates were spun down $\left(10 \mathrm{~min}, 15,000 \mathrm{~g}\right.$ at $\left.4^{\circ} \mathrm{C}\right)$. Supernatants were collected and amino acids levels were determined using a Waters HPLC fluorometric detection system (Waters, Milford, MA). Data were computed with the Millenium software from Waters, identification and quantification of peaks were achieved by comparison with standard solutions.

\section{Statistical Analysis}

Values are indicated as mean \pm SEM. Paired Student's $t$-test or a one-way ANOVA with the Bonferroni post hoc test were used for comparison. Statistical analysis was performed using Origin 8.0: ns: not significant; ${ }^{*} P<0.05$; ${ }^{* *} P<0.01 ;{ }^{* *} P<0.001$. The number of cells used for each experiment illustrated by a figure is indicated in the legends.

\section{Results}

As already described, astrocytes can be visualized in slices with the fluorescent marker sulforhodamine 101 (SR-101), which allows to distinguish them from neurons (Kafitz et al., 2008). Moreover, fluorescent cells displayed a linear current response to incremental depolarizing voltage steps from -150 $\mathrm{mV}$ to $+40 \mathrm{mV}$ indicating that they are passive astrocytes (Fig. 1A,B). In the presence of blockers of ionotropic, metabotropic GABA, and glutamate receptors, and of GABA transporters and Kir channels (see materials and methods), low frequency electrical stimulation $(0.1 \mathrm{~Hz})$ evoked fast inward currents that were fully blocked by DL-TBOA $(100 \mu M)$, a specific blocker of glutamate transporters, indicating that they were mediated by the activation of glutamate transporters (Fig. 1B). This inward current is referred as synaptically evoked transporter current (STC). 


\section{GLLA}

A

B
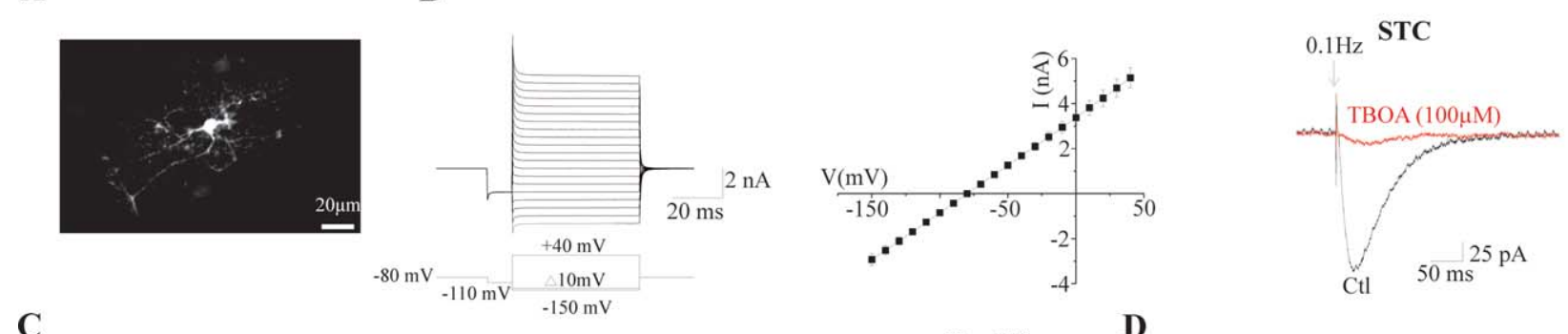

$\mathrm{C}$
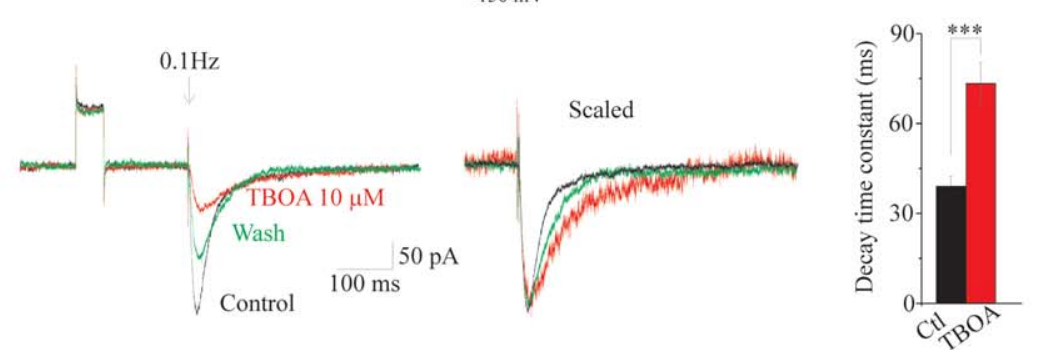

D

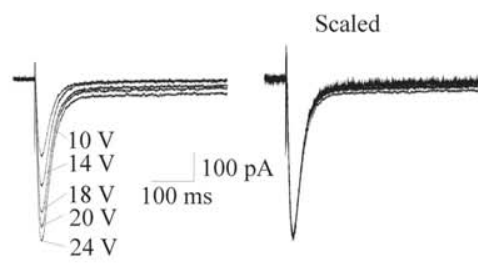

FIGURE 1: Low concentration of TBOA slows the time course of synaptically activated transporter current (STC). (A) Image of an astrocyte recorded in the deep layer of the neocortical slice with a pipette filled with a potassium gluconate (KGluc.) based solution and containing biocytin. (B) Left: Current response to $50 \mathrm{~ms}$ depolarizing voltage steps from -150 to $40 \mathrm{mV}$ (10 mV increment) and showing the typical linear I/V relation characteristic of passive astrocytes (mean of 17 cells). Right: Traces showing transporter current evoked by electrical stimulation at $0.1 \mathrm{~Hz}$ and recorded in absence (black trace, mean of 5 events) and in presence of DL-TBOA (red trace, mean of 5 events $10 \mathrm{~min}$ after the installation of TBOA $100 \mu \mathrm{M}$ ). (C) Traces showing STC in the absence (black, control) or the presence of a low concentration of DL-TBOA (10 $\mu \mathrm{M}$, red) and after the washout of the drug (green). The three traces were scaled to the control amplitude to show that TBOA slows STC time course. Each stimulus was preceded by a depolarizing step of $2 \mathrm{mV}$ during $50 \mathrm{~ms}$. Histograms represent the quantification of STC decay time constant before and after the installation of TBOA ( $n=6$ cells). (D) STC evoked by stimulus intensities ranging from 10 to $24 \mathrm{~V}$. STC were scaled to the maximal amplitude to show that the time course is not dependent to current amplitude. Same results were obtained in two other cells. [Color figure can be viewed at wileyonlinelibrary.com]

\section{Partial Blockade of Glutamate Transporters Slows STC and NMDAR-EPSC Time Course}

Our goal was to determine if the inactivation of GS could affect STC and evoked EPSCs. We first wondered how STC would be impacted when this uptake was artificially reduced using a low concentration of DL-TBOA $(10 \mu M)$, close to the $\mathrm{IC}_{50}$ of GLT1. We observed that TBOA reduced STC peak amplitude by $51 \pm 5 \%$. In addition, the decay time constant of STC was more than two times slower than STC recorded in the absence of TBOA (Fig. 1C). This prolonged time course did not result from the decrease in STC amplitude since in the absence of TBOA, the decay time was stable for STC evoked by a wide range of stimulus intensity (Fig. $1 D)$. We next analyzed the consequences of TBOA on the kinetic and charge transfer of the EPSC evoked by NMDA activation in pyramidal neurons. We observed that both the time course and charge transfer of NMDAR-EPSC were increased after the application of TBOA (Fig. 2A,B). We performed same analysis on AMPAR-EPSC and did not find any effects of TBOA $(10 \mu M)$ on the EPSC (Fig. 2C,D). These data are in keeping with other studies showing that NMDA but not AMPAR are impacted by the partial inhibition of EAATs unless the desensitization of AMPAR was relieved (Tzingounis and Wadiche, 2007). According to other studies, it is likely that the selective enlargement of NMDAR-
EPSC after TBOA is a consequence of an increase of glutamate diffusion and peri/extrasynaptic activation of NMDA receptors due to an insufficient uptake of glutamate by glial glutamate transporters (Arnth-Jensen et al., 2002; Diamond, 2001; Marcaggi and Attwell, 2004). We then focused our attention on decay kinetic in the next following experiments.

\section{Intracellular Elevation of Glutamate Concentration Affects STC Time Course Evoked by Short Burst of High Frequency Stimulation (HFS)}

Immunogold electromicroscopic studies have shown that inactivation of GS with L-methionine-DL-sulfoximine (MSO) leads to intracellular accumulation of glutamate in astrocytes (Laake et al., 1995; Perez et al., 2012). In addition the presence of $\mathrm{Na}^{+}$and glutamate in the cytosol may affect glutamate transport (Barbour et al., 1991; Otis and Jahr, 1998). We thus wondered if intracellular glutamate accumulation would change STC time course. For this purpose, we recorded astrocytes with patch pipettes filled with 1, 3, $10 \mathrm{~m} M$ glutamate or devoid of glutamate (0 glutamate) but which contained in all cases $10 \mathrm{mM} \mathrm{Na}{ }^{+}$. First, we measured the input resistance of the cells and observed that intracellular elevation of glutamate did not have significant consequences on this parameter (Fig. 3F). Then, we analyzed the decay time constant of STC elicited at low frequency stimulation 
A

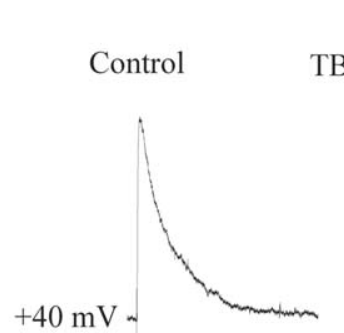

$+40 \mathrm{mV}$

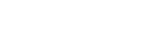

C

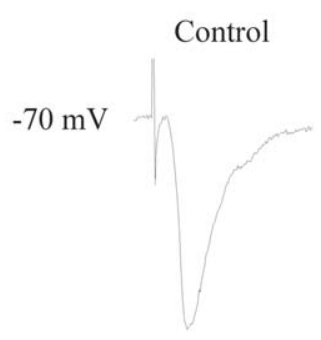

NMDAR-EPSC
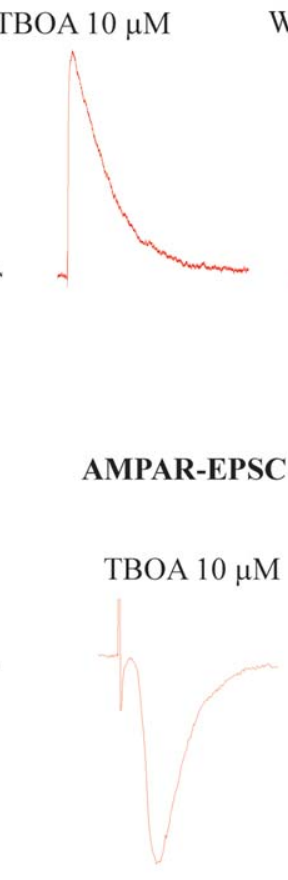

B
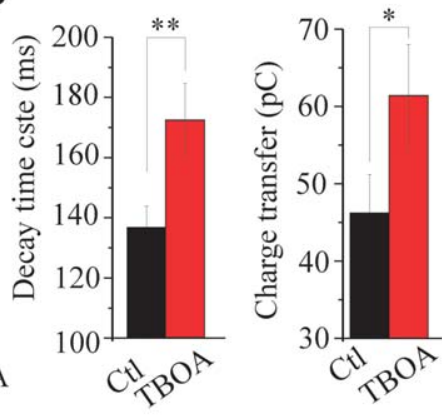

D

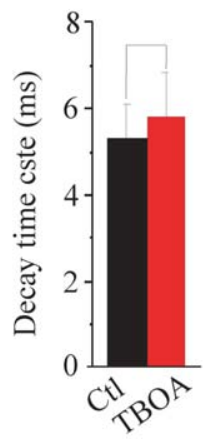

FIGURE 2: Low concentration of TBOA prolongs the decay of NMDAR but not of AMPAR-mediated EPSC. (A, C) NMDAR-EPSCs evoked at $+40 \mathrm{mV}(\mathrm{A})$ and AMPAR-EPSCs evoked at $-70 \mathrm{mV}$ (C) by electrical stimulation at $0.1 \mathrm{~Hz}$ and recorded with a pipette filled with a cesium gluconate (CsGluc.) based solution, in control (black), $10 \mathrm{~min}$ after the installation of TBOA (10 $\mu M$, red) and after the washout of the drug (green). Traces are scaled to the control amplitude for comparison of the decay. (B, D) Histograms represent the quantifications of the decay time constant (left) and the charge transfer (right) of NMDAR-EPSC (B, $n=9$ cells) and AMPAR-EPSC (D, $n=8$ cells) in control and after TBOA. [Color figure can be viewed at wileyonlinelibrary.com]

$(0.1 \mathrm{~Hz})$. No correlation between decay time constant of STC and the intracellular concentration of glutamate was observed. Indeed, the decay time of STC recorded with $1 \mathrm{~m} M$ glutamate in the patch pipette was similar to the one recorded with $10 \mathrm{~m} M(P=0.34)$ but the 2 values were significantly smaller than the decay of STC recorded in absence or with $3 \mathrm{~m} M$ glutamate in the pipette $(P<0.001$, Figs. 3E and $6 \mathrm{C})$. We thus assumed that intracellular glutamate elevation in astrocytes had no major consequence on glutamate uptake when the transmitter is released at low frequency. We then wondered if such conclusion would also hold true when glutamate is released during high frequency stimulation. For this purpose, we used the same experimental procedure as described by Diamond and Jahr (2000) in which STC evoked by high frequency stimulation was extracted by subtracting transporter current evoked by 11 pulses at $100 \mathrm{~Hz}$ to the one evoked by 10 pulses at $100 \mathrm{~Hz}$ and the decay time of the current $\left(\mathrm{STC}_{\mathrm{HFS}}\right)$ compared with the one evoked at $0.1 \mathrm{~Hz}$ (STC $\mathrm{LFS}_{\mathrm{LS}}$, Fig. 3A). We observed that the decay time constant was slightly increased in $0-1 \mathrm{~m} M$ glutamate recording conditions, leading in both cases to a $\tau$ decaySTC $\mathrm{HFS}_{\mathrm{HFS}} / \tau$ decaySTC $\mathrm{LFS}_{\mathrm{LF}}$ ratio of $\sim 1.25$ (Figs. $3 \mathrm{~B}, \mathrm{E}$ and $6 \mathrm{C}$ ); this value is stronger than the one reported by Diamond and Jahr in the CA1 region of the hippocampus (ratio of $\sim 1$ ). However, a much larger increase in STC decay time was observed in cells filled either with 3 or $10 \mathrm{~m} M$ glutamate, leading to a more important $\tau$ decaySTC $\mathrm{HFS}_{\mathrm{HF}} / \tau$ decaySTC $\mathrm{LFS}_{\mathrm{LF}}$ ratio (Fig. 3C-E). These data suggested that glutamate accumulation in astrocytes may reduce glutamate uptake by the transporters particularly when the transmitter is released during a short burst of high frequency stimulation.

\section{Glutamine Is Selectively Decreased in Cortical Slices After Intraperitoneal Injection of MSO}

To determine the possible impact of GS on STC time course, MSO was administered intraperitoneally in rats $24 \mathrm{~h}$ before their sacrifice and the electrophysiological recordings of astrocytes in neocortical slices (see Materials and Methods section). First, to ensure that GS was inhibited, the concentration of glutamine, as well as other amino acids (glutamate, GABA, aspartate, alanine) in slices were determined by HPLC and their content (expressed in $\mathrm{nmol} / \mathrm{g}$ of proteins) compared with slices from sham (saline injected) animals. As shown in Table 1, glutamine was decreased by $\sim$ three times in 
A

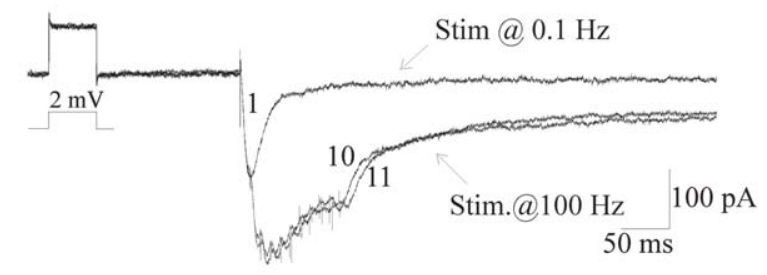

C

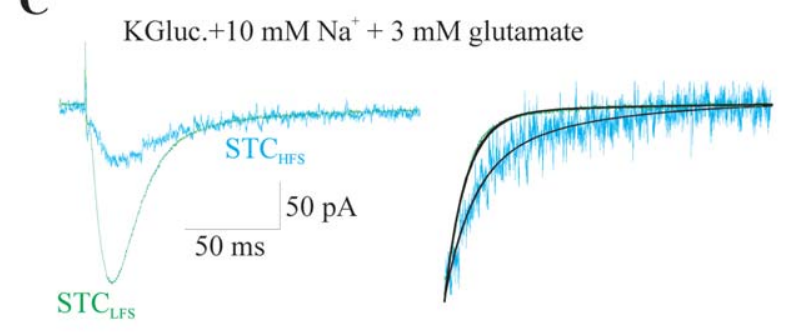

$\mathbf{E}$

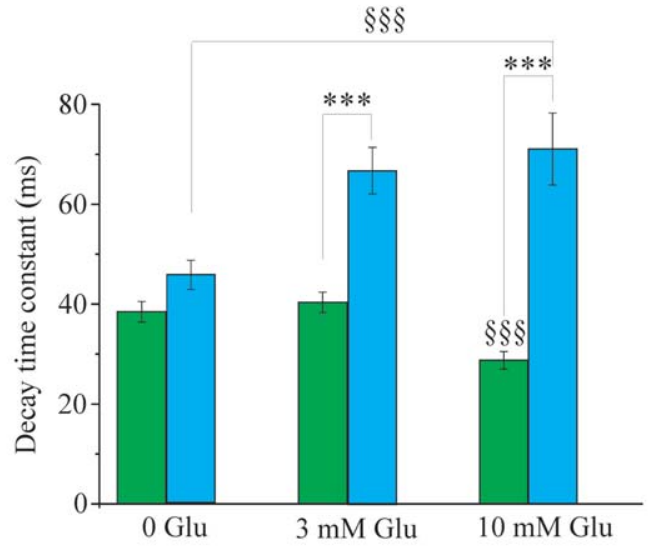

B

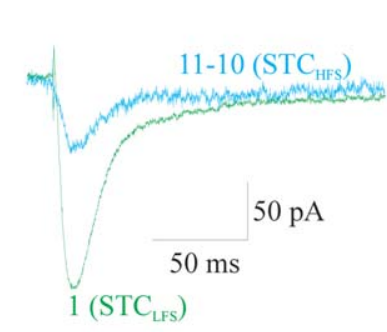

D

KGluc. $+10 \mathrm{mM} \mathrm{Na}^{+}+10 \mathrm{mM}$ glutamate
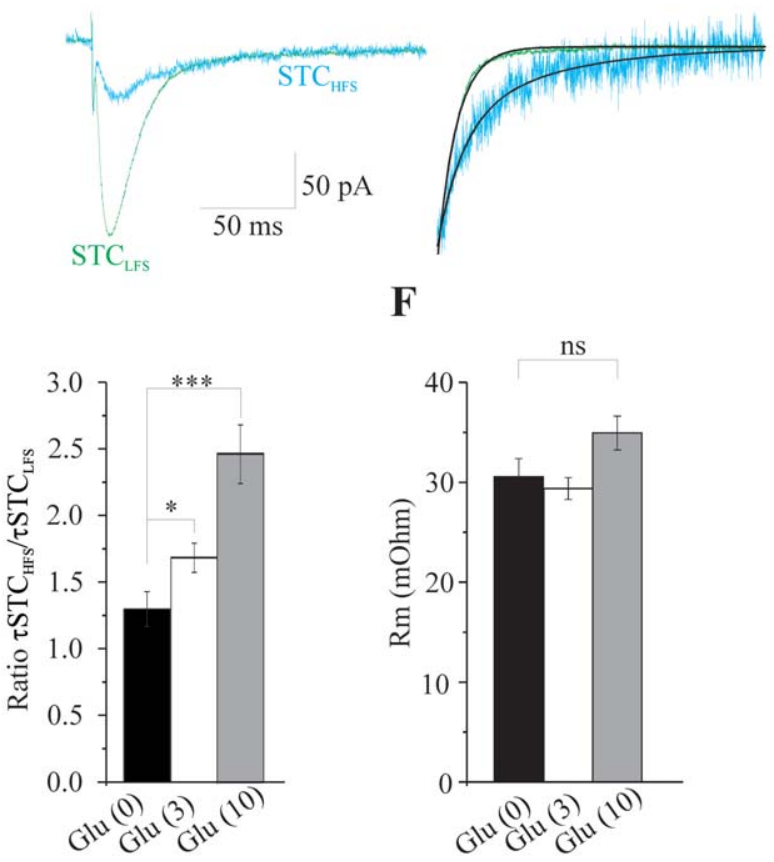

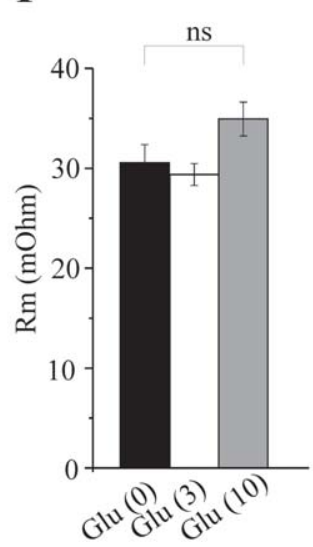

FIGURE 3: Intracellular elevation of glutamate concentration in astrocytes slows STC time course. (A) Superimposed STCs evoked at 0.1 $\mathrm{Hz}(1)$ and at $100 \mathrm{~Hz}$ (10 and 11 pulses) in a cell recorded with a pipette filled with a KGluc. based solution and containing $10 \mathrm{mM} \mathrm{Na}^{+}$

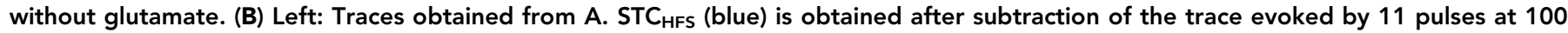
$\mathrm{Hz}$ from the one evoked by 10 pulses at $100 \mathrm{~Hz}$. This current is superimposed on STC $\mathrm{LFs}_{\mathrm{LF}}$ evoked at $0.1 \mathrm{~Hz}$ (green). Right: STC $\mathrm{HFS}_{\mathrm{H}}$ was scaled and aligned to the peak amplitude of $S_{T C} C_{L F}$ to compare the decays. Black lines are the exponential fits of the decays of both $\mathrm{STC}_{\mathrm{HFS}}$ and $\mathrm{STC}_{\mathrm{LFS}}$ (C, D) Same as in B but in astrocytes recorded with pipettes containing 3 and $10 \mathrm{mM}$ of L-glutamate (C and D, respectively). (E) Left: Histograms represent the quantification of the decay time constant (weight average) of both STC $\mathrm{LFS}_{\mathrm{LF}}$ (green) and STC $_{\text {HFS }}$ (blue) in astrocytes recorded in absence or in the presence of 3 and $10 \mathrm{mM}$ glutamate in the patch pipette. Astrocytes recorded without glutamate in the pipette: $n=9$ cells, 36 series of stimulation at 0.1 and $100 \mathrm{~Hz}$. Astrocytes recorded with $3 \mathrm{mM}$ glutamate in the pipette: $n=11$ cells, 29 series of stimulation. Astrocytes recorded with $10 \mathrm{mM}$ glutamate in the pipette: $n=8$ cells, 37 series of stimulation. ${ }^{*}$ Comparison of the decay time of $\mathrm{STC}_{\mathrm{HFS}}$ with $\mathrm{STC}_{\mathrm{LFS}}$ for each conditions of recording; $\S$ comparison with the 0 glutamate condition. Right: histograms represent the ratio of the decay time constant of $\mathrm{STC}_{\mathrm{HFS}} / \mathrm{STC} \mathrm{LFF}_{\mathrm{LF}}$. The ratio was calculated for each cell and the values were pooled together. (F) Histograms represent the mean input resistance of the three groups of cells. [Color figure can be viewed at wileyonlinelibrary.com]

neocortical slices from MSO treated animals as compared with slices from saline injected animals. This decrease was observed only for glutamine and the other amino acids were not significantly affected. We performed the same measurements in hippocampal slices and found that glutamine was also selectively decreased. Together, these data indicated that in vivo injection of MSO was efficient to inhibit GS, in agreement with previous studies in which the activity of GS was measured (Brusilow et al., 2010; Sellinger et al., 1968).
The inhibition of GS can be further demonstrated electrophysiologically through the analysis of tonic NMDARmediated current in pyramidal cells that is unmasked after complete inhibition of glutamate transporters with DLTBOA $(100 \mu M)$. This current, that is insensitive to voltage gated $\mathrm{Na}^{+}$and $\mathrm{Ca}^{2+}$ channel blockers and to blocker of glutamate vesicular transporters or tetanus toxin, is proposed to be due to the leakage of glutamate from astrocytes (Cavelier and Attwell, 2005; Demarque et al., 2002; Jabaudon et al., 
TABLE 1: Concentrations (Expressed in $\mathrm{nmol} / \mathrm{g}$ of Protein) of Glutamine, Glutamate, GABA, Aspartate and Alanine in Neocortical and Hippocampal Slices $(400 \mu M$ Thick) Measured $24 \mathrm{~h}$ After the Intraperitoneal Injection of Saline Solution ( $0.09 \%$ of $\mathrm{NaCl}, n=4$ rats) or $\mathrm{MSO}(170 \mathrm{mg} / \mathrm{kg}, n=4$ rats $)$

Glutamine Glutamate GABA Aspartate

\begin{tabular}{lccccc|} 
Neocortex & \multicolumn{3}{l}{. } \\
Saline & $7.63 \pm 1.29$ & $87.25 \pm 9.63$ & $46.22 \pm 6.53$ & $36.67 \pm 16.52$ & $6.41 \pm 1.25$ \\
MSO & $2.65 \pm 0.71^{*}$ & $85.4 \pm 8.71$ & $49.17 \pm 7.84$ & $33.68 \pm 9.22$ & $8.13 \pm 2.59$ \\
Hippocampus & & & & \\
Saline & $14.4 \pm 3.17$ & $119.26 \pm 11.23$ & $99.17 \pm 21.7$ & $41.52 \pm 10.55$ & $8.9 \pm 1.73$ \\
MSO & $3.11 \pm 1.04^{*}$ & $101.4 \pm 11.14$ & $71.27 \pm 20.2$ & $27.74 \pm 7.05$ & $8.34 \pm 2.28$ \\
MSO decreases significantly the amount of glutamine but has no effect on the other amino acids.
\end{tabular}

1999; Le Meur et al., 2007). Different studies have demonstrated that this current is increased in pyramidal neurons from cortical slices incubated with MSO (Cavelier and Attwell, 2005; Jabaudon et al., 1999; LeMeur et al., 2007). We tested if we can get same results in slices from MSO treated rats. In the continuous presence of TTX, and of AMPA and $\mathrm{GABA}_{\mathrm{A}}$, receptors antagonists, application of DL-TBOA induced at $+40 \mathrm{mV}$ an outward current with $\sim 3$ times larger density in slices from MSO-treated animals than from sham animals (Fig. 4). This current was reversed by D-APV (50 $\mu M$, data not shown), indicating that it was mediated by NMDA receptors. Therefore, these data support that intraperitoneal injection of MSO had efficiently inhibited GS.

Another important control was also to evaluate if the inactivation of GS has any consequences on transmitter release with our protocol of stimulation. Notably it was important to determine if postsynaptic responses evoked by LFS and HFS (EPSC $\mathrm{LFS}_{\mathrm{LF}}$ and $\mathrm{EPSC}_{\mathrm{HFS}}$ ) were stable with the iteration of the short burst at $100 \mathrm{~Hz}$. Different studies have shown that GS activity is important to sustain synaptic transmission (Marx et al., 2015; Tani et al., 2010, 2014). We recorded AMPAR-mediated EPSC and performed 10 series of stimulation each consisting of 5-10 stimuli at $0.1 \mathrm{~Hz}$ (LFS) followed by a stimulation at $100 \mathrm{~Hz}$ for $100 \mathrm{~ms}$ (HFS), with a delay of $30 \mathrm{~s}$ between each series; a stimulation protocol that is close to the one used for STC. The charge transfer of ${ }_{\text {AMPAR-EPSC }}$ LFS and AMPAR-EPSC $C_{\mathrm{HFS}}$ were expressed as percentage of the respective response evoked by LFS and HFS of the first series. There was no major variation in the synaptic response evoked by LFS and HFS in slices from saline and MSO treated rats (Fig. 5A,B). Moreover, both the duration of the responses evoked by HFS and the ratio of the charge transfer of AMPAR-EPSC $\mathrm{HFS}_{\mathrm{HF}}$ AMPAR-EPSC $\mathrm{LFS}_{\mathrm{LF}}$ were stable and not significantly different in slices from the 2 groups of animal (Fig. 5B). The decay time constant of AMPAR-EPSC $_{\mathrm{LFS}}$ was also not affected in pyramidal cells from saline and MSO treated rats (saline: $5.16 \pm 0.5 \mathrm{~ms}$; MSO $5.1 \pm 0.43 \mathrm{~ms}$ ).

In separate experiments, we have also recorded spontaneous AMPAR-EPSC and did not find any differences in the
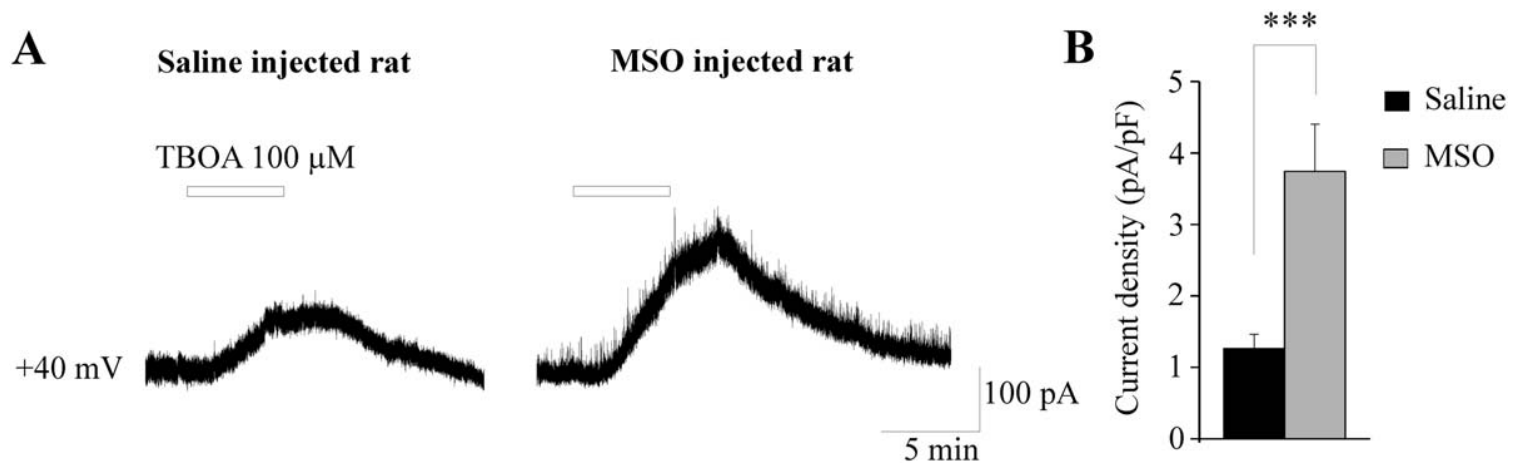

FIGURE 4: Endogenous NMDAR-mediated current unmasked after glutamate transporters inhibition is enhanced in animal treated with MSO. (A) Currents evoked at $+40 \mathrm{mV}$ in neocortical pyramidal cells after the application of DL-TBOA (100 $\mu M)$ and recorded in presence of TTX $(1 \mu M)$, NBOX $(20 \mu M)$, LY341495 $(1 \mu M)$, gabazine $(5 \mu M)$, in slices obtained from rats $24 \mathrm{~h}$ after intraperitoneal injection of saline solution $(0.09 \% \mathrm{NaCl})$ or $\mathrm{MSO}(170 \mathrm{mg} / \mathrm{kg})$. (B) Mean current density evoked in neurons from the two groups of rat: Saline $n=14$ cells; MSO: $n=14$ cells. 
A

Serie \# 1

Saline LFS HFS

MSO
Serie \# 10

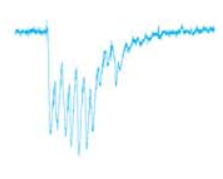

Superimposed

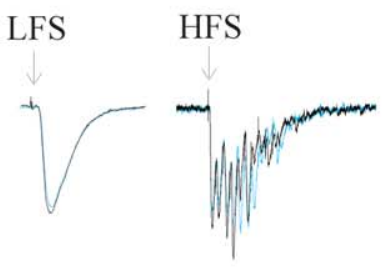

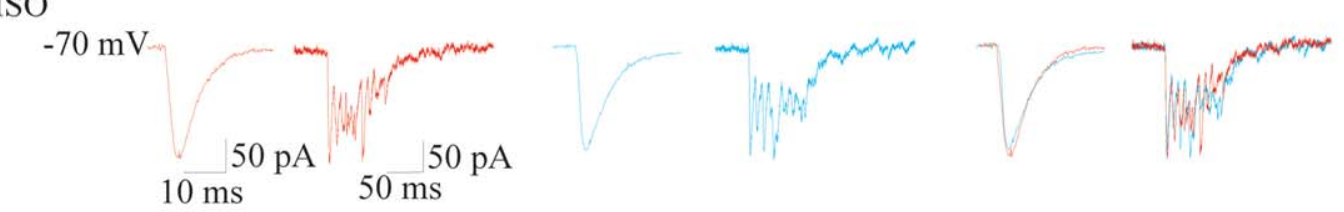

B
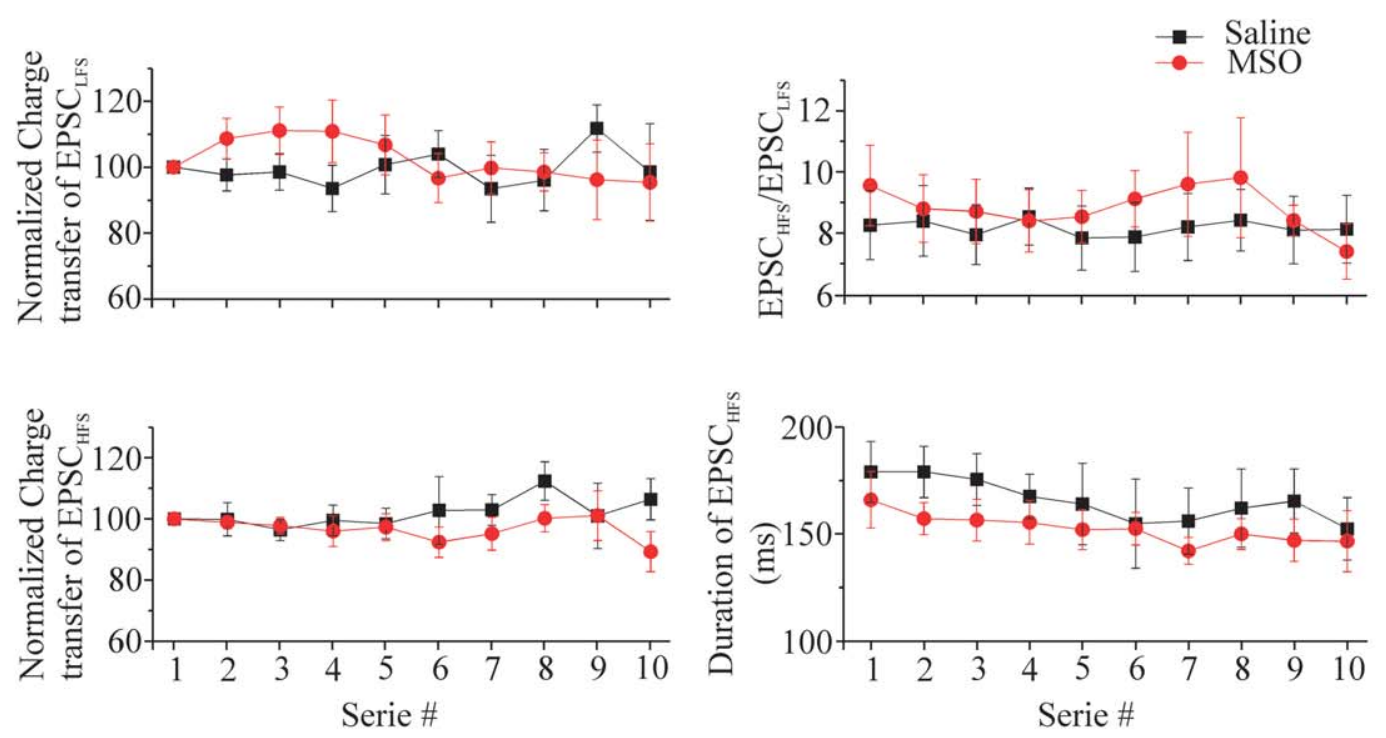

C
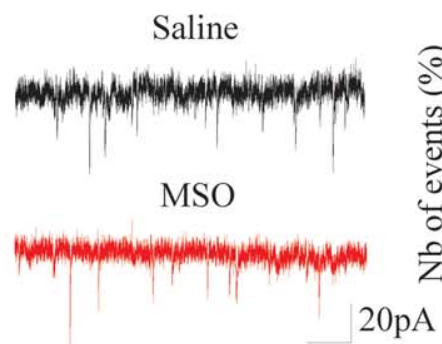

$250 \mathrm{~ms}$

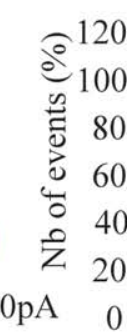

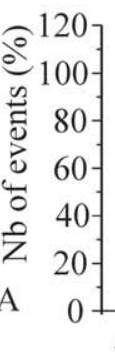

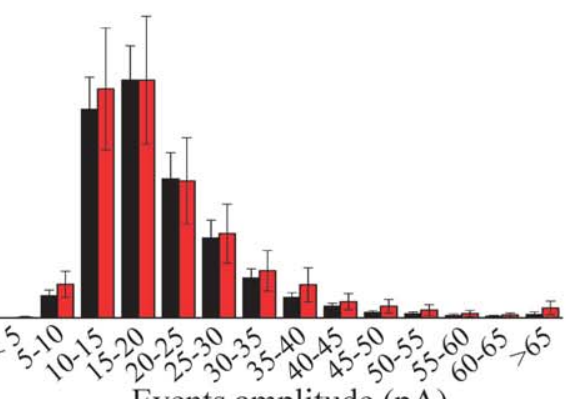

Events amplitude (pA)

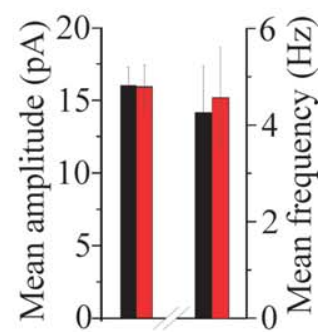

FIGURE 5: Evoked and spontaneous AMPAR-mediated EPSC are not impacted by the inhibition of glutamine synthase. (A) AMPAR-EPSC evoked at low frequency stimulation $\left(0.1 \mathrm{~Hz}\right.$, AMPAR-EPSC $_{\mathrm{LFS}}$ ) and high frequency stimulation (10 stimuli at $100 \mathrm{~Hz}, \mathrm{AMPAR}_{\mathrm{EPSC}} \mathrm{HFS}_{\mathrm{H}}$ ) in slices from saline and MSO treated rats during the 1st and the 10th series of stimulation. Traces of the two series are superimposed and show that the iteration of the stimulation does not have major effects on EPSC $_{\mathrm{LFS}}$ and $\mathrm{EPSC}_{\mathrm{HFS}}$. (B) Left: graphs represent the mean charge transfer of EPSC $_{\mathrm{LFS}}$ (top graph) and EPSC $\mathrm{HFS}_{\mathrm{HFS}}$ (bottom graph) in the two groups of rat for the ten series of stimulation. For each experiment the values have been normalized to the charge transfer evoked during the first series of stimulation. In total the mean charge transfer of $\mathrm{EPSC}_{\mathrm{LFS}}$ and $\mathrm{EPSC}_{\mathrm{HFS}}$ was: $1.18 \pm 0.03 \mathrm{pC}$ and $9.22 \pm 0.39 \mathrm{pC}$, respectively for saline treated rats and $1 \pm 0.04 \mathrm{pC}$ and $7.54 \pm 0.22 \mathrm{pC}$ for MSO treated rats. Right top graph: ratio of the charge transfer of $\mathrm{EPSC}_{\mathrm{HFS}} / \mathrm{EPSC}_{\mathrm{LFS}}$ for the ten series of stimulation. Bottom graph: duration of the response evoked by HFS. Pyramidal neurons recorded from saline treated rats: $n=10$ cells/3 rats. Pyramidal neurons recorded from MSO treated rats: $n=12$ cells/3 rats. (C) Left: spontaneous AMPAR- mediated EPSC recorded in pyramidal neurons at $-70 \mathrm{mV}$ from saline and MSO treated rats. Right: histogram represents the amplitude distribution of spontaneous events (bin of $5 \mathrm{pA}$ ). The number of events is expressed as percentage of the maximal of events obtained in a bin. For the two groups of rat the most frequent events have amplitude ranging between 15 and 20 pA. The histograms corresponding to the pyramidal neurons of saline treated rats are from 21,357 events recorded in 15 cells/2 rats and in MSO treated rats from 39,775 events recorded in 16 cells/2 rats. (D) Histograms represent the mean amplitude and frequency of the AMPA events. [Color figure can be viewed at wileyonlinelibrary.com] 
frequency or in events amplitude (Fig. 5C). The amplitude distribution of the events (bin of $5 \mathrm{pA}$ ) was similar in both groups of slice. Together our data indicated that inhibition of GS had no major consequences on spontaneous and evoked transmitter release with our stimulation protocol.

\section{Inhibition of Glutamine Synthase by MSO Slows STC Time Course Evoked by HFS}

We then determined whether GS inhibition had any consequence on STC time course. For this purpose we recorded STC with patch pipettes filled with $10 \mathrm{mM} \mathrm{Na}{ }^{+}$and $1 \mathrm{~m} M$ glutamate, closed to the physiological concentrations (Chatton et al., 2000; Lebon et al., 2002; Nedergaard et al., 2002; Zhou et al., 2014). Decay time constant of both $S_{T C}$ LFS and $\mathrm{STC}_{\mathrm{HFS}}$ evoked during each series of stimulations were measured in neocortical astrocytes from saline and MSO treated animals. First, as for cells loaded with glutamate, inhibition of GS did not have significant consequences on input resistance of astrocytes (Fig. 6E). Second, we observed that the decay time constant of $S_{T C}$ HFS but not of $S_{T C} C_{L F S}$ was significantly affected by the inactivation of GS. Thus, the decay time constant of $S_{T C} C_{H F S}$ was about two times slower in MSO treated rats leading to a large increase in $\tau$ decaySTC $\mathrm{HFS}_{\mathrm{HF}} / \tau$ decaySTC $\mathrm{LFS}_{\text {ratio }}$ (Fig. $6 \mathrm{~A}-\mathrm{C}$ ). In spite of some variations this difference in current kinetic was maintained when stimulations were repeated. We have also measured the charge transfer of $S_{T C} C_{L F}$ and $S T C_{H F S}$. We observed that for similar values of $\mathrm{STC}_{\mathrm{LFS}}$, there was also no difference in the charge transfer of $\mathrm{STC}_{\mathrm{HFS}}$ in astrocytes from both groups of rat (Fig. 6D). Together, our data suggest that same amount of glutamate is reuptake by glutamate transporters but this takes longer time in astrocytes inactivated for GS when glutamate is released by HFS.

\section{Inhibition of GS Increases Peri/Extrasynaptic Activation of NMDA Receptors}

The increase in $S T C_{H F S}$ decay time constant in astrocytes inactivated for GS suggested that glutamate transporters close to synaptic sites are overwhelmed by glutamate released during HFS. This should facilitate the spillover of the transmitter out of the synaptic cleft and the activation of NMDA receptors located at peri/extrasynaptic sites leading to an amplification of NMDAR-mediated EPSC evoked by HFS. We tested this hypothesis and recorded NMDAR-mediated EPSC. We calculated the ratio of the charge transfer of NMDAREPSC $_{\mathrm{HFS}} / \mathrm{NMDAR-EPSC} \mathrm{LFS}_{\mathrm{LF}}$ for each series of stimulation in pyramidal neurons from both $\mathrm{MSO}$ and saline injected rats as we did for AMPAR-EPSC. Figure 7A-C shows that the ratio was consistently and significantly stronger in pyramidal neurons from MSO treated rats. On average, the charge transfer of NMDAR-EPSC $\mathrm{HFS}_{\mathrm{S}}$ was stronger in these pyramidal neurons while NMDAR-EPSC LFS $_{\text {was }}$ even slightly lower compared with the values of pyramidal neurons from saline treated rats (Fig. 7C). Also, in line with the absence of effects of GS inhibition on $S_{T C}$ LFS decay time constant, the time course of NMDAR-EPSC $\mathrm{LFS}_{\mathrm{LF}}$ was not significantly different in pyramidal neurons from the 2 groups of rat (Fig. 7D). We next examined the peri/extrasynaptic NMDA component of NMDAR-EPSC $\mathrm{HFS}_{\mathrm{HFS}}$ (Fig. 7E-G). This component was isolated from the synaptic response using the irreversible NMDA open channel blocker MK-801 (40 $\mu M)$. After 5 min of stimulation at $0.1 \mathrm{~Hz}$, MK-801 $(40 \mu M)$ was installed until the full abolishment of the response. MK-801 was then washed out and HFS (same stimulation as above) was applied every minutes. These stimulations consistently evoked a response with a slow onset that was fully abolished by DAPV $(50 \mu M)$ indicating that they were mediated by peri/ extrasynaptic NMDA receptors (Fig. 7E). However, we cannot fully exclude a contribution of some synaptic NMDA receptors to the response because HFS may recruit additional synaptic connections that were not active during application of LFS in MK801. We calculated the charge transfer of the NMDARs mediated response after MK801 (extrasynaptic response) normalized to the charge transfer before the application of the blocker (synaptic response) in pyramidal neurons from the two groups of rat. The responses were significantly stronger in MSO treated animal (Fig. 7F,G). On an average, the responses evoked by extrasynaptic receptors during the 10 series of HFS were $\sim 45 \%$ larger in MSO treated animals while synaptic NMDAR-EPSC $\mathrm{LFs}_{\mathrm{LF}}$ preceding the application of MK-801 were not different in the two groups of animal.

\section{Discussion}

Electron microscopy studies performed in the somatosensory cortex demonstrated that most of glutamate transporters are present in astrocytic processes and have a prominent perisynaptic localization that may contribute to restrict glutamate spillover (Melone et al., 2009). Moreover, a recent study provided evidences that GLT1 in astrocytes are highly mobile and that once bound by glutamate, they move away from the synapse allowing their replacement by unbound transporters, a process that may favor efficient clearance of glutamate from synaptic cleft (Murphy-Royal et al., 2015). Here, we show that these characteristics may be insufficient for a rapid clearance of glutamate when glutamate catabolism in astrocytes is altered. We provide evidences that GS activity regulates STC time course when glutamate is released by short burst of high frequency stimulation but not by low frequency stimulation. This indicated that the conversion of glutamate by GS is a fundamental process for proper glutamate transporters function. It is likely that the consequences of GS inactivation 
A ₹-Saline
- - MSO

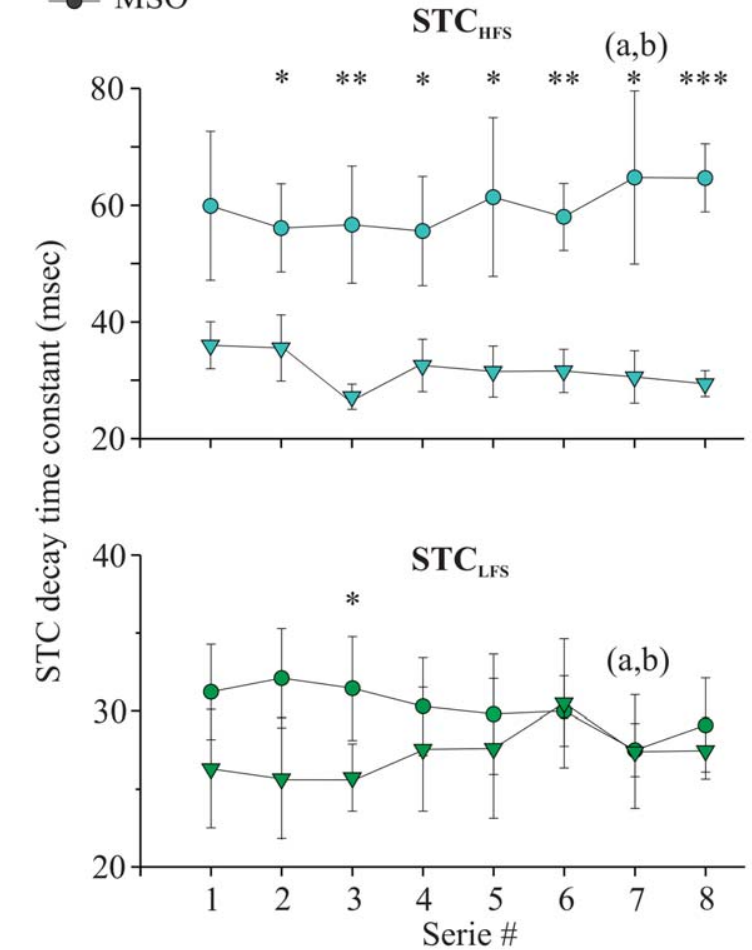

C

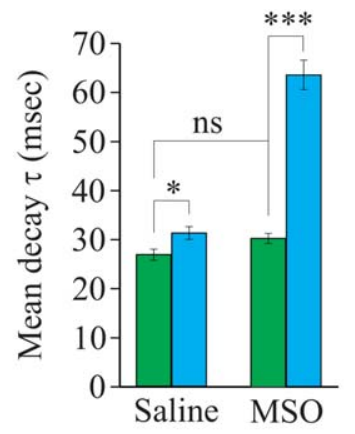

D

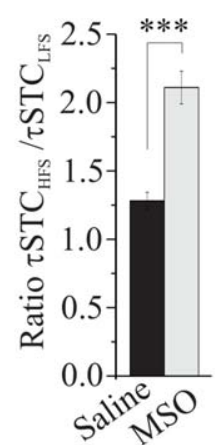

B
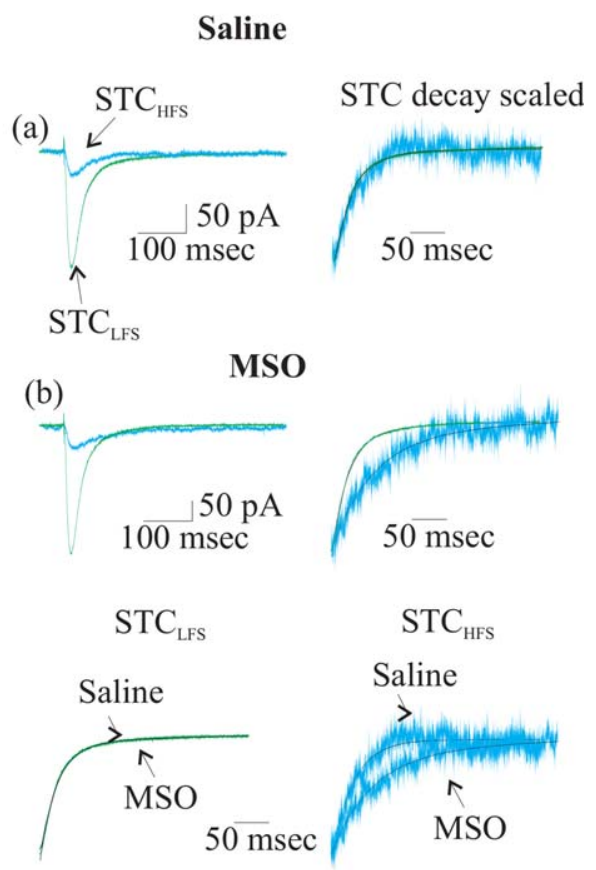

E

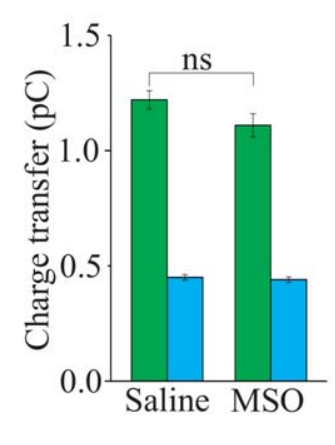

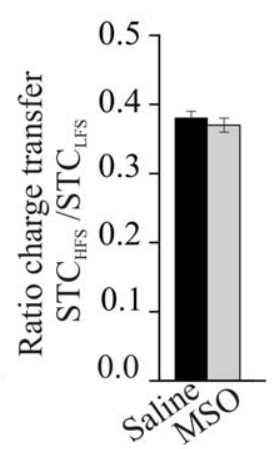

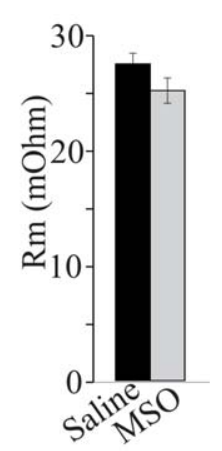

FIGURE 6: Inhibition of glutamine synthase increases STC time course. (A) Graph showing the decay time constant of both STC HFS $_{\text {(upper }}$ graph, blue) and $\mathrm{STC}_{\mathrm{LFS}}$ (middle graph, green) during 8 series of stimulation (see Materials and Methods section) in astrocytes from saline (triangle, $n=12$ cells $/ 3$ rats) and MSO treated rats (circle, $n=10$ cells $/ 3$ rats). (B) Left: superimposed STC $_{\mathrm{LFs}}$ and $\mathrm{STC}_{\mathrm{HFS}}$ from saline (upper traces) and MSO (middle traces) treated rats corresponding to series \#7 indicated by a letter in A. Right: STC $\mathrm{HFS}_{\mathrm{H}}$ was Scaled and aligned to the peak amplitude of STC $\mathrm{LFS}_{\mathrm{LF}}$ to compare the decays. Black lines are the exponential fits of the decays of both STC $_{\mathrm{HFS}}$ and STC $\mathrm{LFS}_{\mathrm{LFS}}$. Bottom traces: STC $\mathrm{LFS}_{\mathrm{LFS}}$ (left) and STC $\mathrm{HFS}_{\mathrm{HFS}}$ (right) from saline and MSO treated rats were scaled and aligned to the peaks to compare the decays. The decay of $\mathrm{STC}_{\mathrm{HFS}}$ is slower in astrocytes from MSO compared with saline injected rats while the decays of

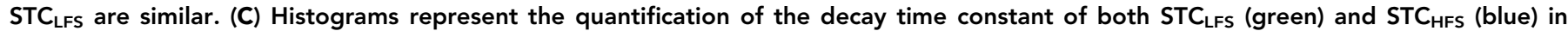
astrocytes from saline and MSO treated rats (left histogram) obtained from pooled data depicted in B for the 8 series of stimulation. Right histograms represent the ratio of $\mathrm{STC}_{\mathrm{HFS}} / \mathrm{STC}_{\mathrm{LFS}}$ decay time constant. The ratio was calculated for each cell and the values were averaged. (D) Same as in C but for the charge transfer of STC. (E) Mean input resistance of the cells from the two groups of rat. [Color figure can be viewed at wileyonlinelibrary.com]

result from an intracellular accumulation of glutamate occurring with the stimulations, since the slowing of STC time course was also observed in the same stimulation conditions of astrocytes recorded with 3-10 $\mathrm{m} M$ glutamate. The tendency of glutamate to accumulate in astrocytes in the absence of GS activity has been demonstrated in both hippocampal astrocytes and Müller cells of the retina with immunogold labelling (Barnett et al., 2000; Laake et al., 1995; Perez et al., 2012), and with electrophysiological recordings of endogenous NMDA current in CA1 pyramidal neurons unmasked after inhibition of glutamate transporters (Cavelier and Attwell, 2005; Demarque et al., 2002; Jabaudon et al., 1999; Le 
A

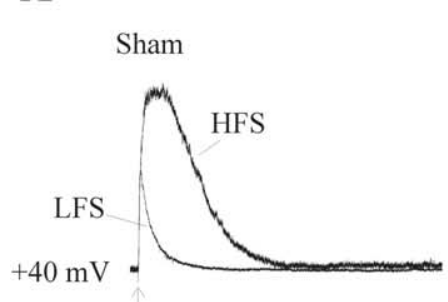

B

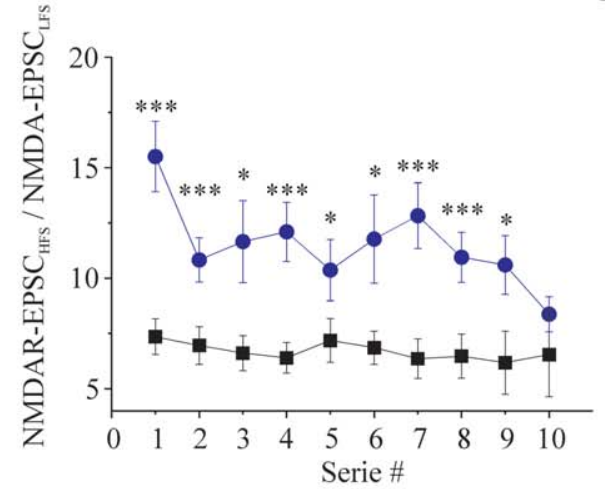

C

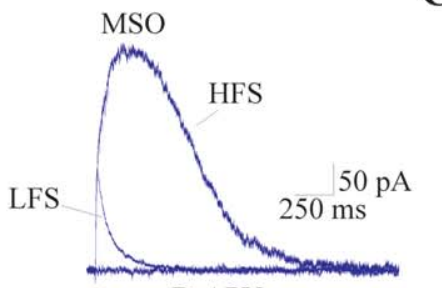

D-APV

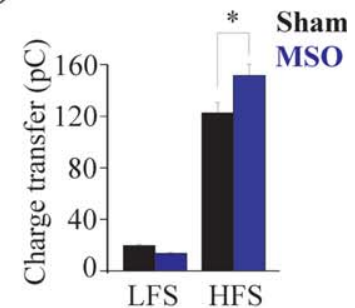

LFS HFS
D

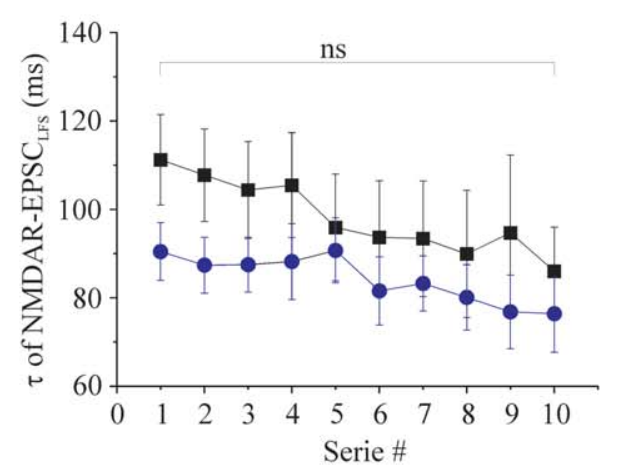

E

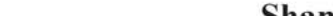

Sham

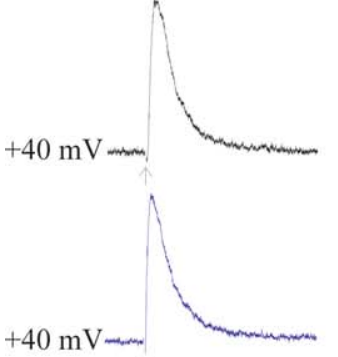

LFS
MK-801 (40 $\mathrm{M})$

MK-801 washout

DL-APV

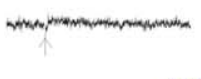

MSO
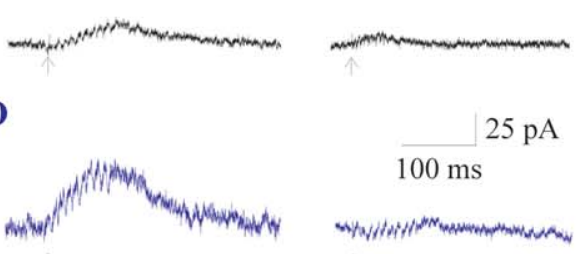

$100 \mathrm{~ms}$

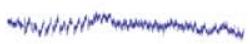

HFS
F

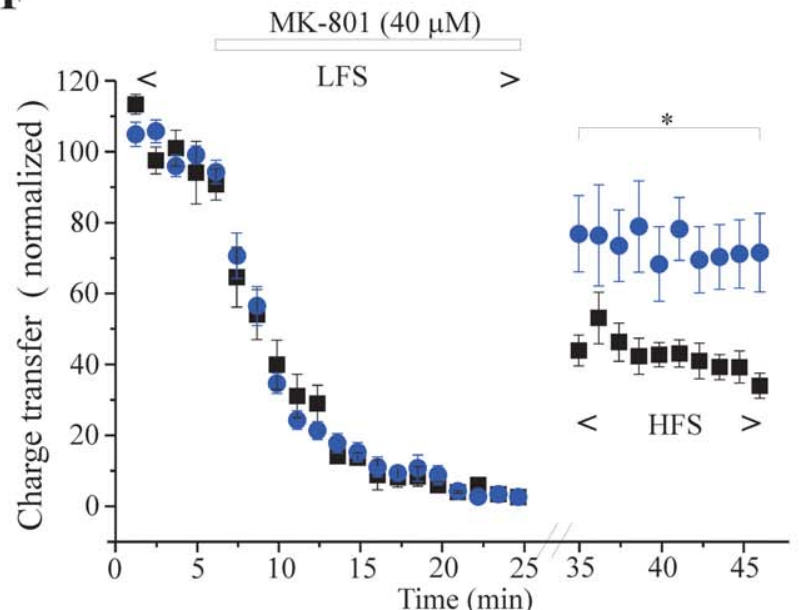

G

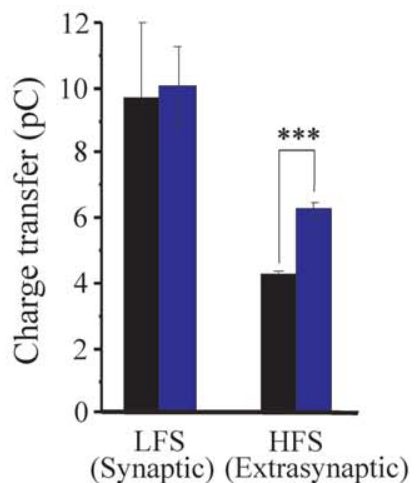

FIGURE 7: Inhibition of glutamine synthase amplifies NMDAR-EPSC evoked by HFS. (A) Superimposed NMDAR-EPSC evoked at 0.1 Hz (LFS) and by 10 pulses at $100 \mathrm{~Hz}$ (HFS) recorded in a pyramidal neuron from saline (left traces, black) and MSO (right traces, purple) treated rats. (B) Ratio of the charge transfer of NMDAR-EPSC $\mathrm{HFS}_{\mathrm{HFS}} / \mathrm{NMDAR}$-EPSC $\mathrm{LFS}_{\mathrm{LF}}$ for each series of stimulation in pyramidal cells from saline ( $n=16$ cells $/ 3$ rats) and MSO treated rats $(n=16$ cells $/ 2$ rats). (C) Histograms represent the mean charge transfer of NMDAREPSC $_{\mathrm{LFS}}$ and NMDAR-EPSC $\mathrm{HFS}_{\mathrm{H}}$ in the two groups of rat. The respective values of NMDAR-EPSC evoked by LFS and HFS for the 10 series of stimulation have been pooled. (D) Graph showing the decay time constant of NMDA-EPSC evoked at $0.1 \mathrm{~Hz}$ in the two groups of rats for the 10 series of stimulation. (E) Traces showing NMDAR-EPSCs evoked at $0.1 \mathrm{~Hz}$ (LFS); 20 min after the installation of MK-801; by 10 pulses at $100 \mathrm{~Hz}$ (HFS) after MK-801 washout; after the addition of D-APV (50 $\mu$ M) in both saline (black) and MSO (purple) treated rats. (F) Graph represents the charge transfer of NMDAR-EPSC for the two groups of rats normalized to the respective values evoked at $0.1 \mathrm{~Hz}$ before the installation of MK-801. Saline: $n=8$ cells $/ 3$ rats; MSO: $n=9$ cells $/ 3$ rats. (G) Histograms represent the mean charge transfer of synaptic NMDAR-EPSC (evoked by LFS) and peri/extrasynaptic stimulation NMDAR-EPSC (evoked by HFS) in the two groups of rats. The respective values of NMDAR-EPSC evoked by LFS and HFS for the 10 series of stimulation have been pooled. [Color figure can be viewed at wileyonlinelibrary.com] 
Meur et al., 2007). Altogether, these data provide evidence that GS is a major enzyme involved in glutamate catabolism. In line with this, metabolic studies have shown that two-third of glutamate released and transported in astrocytes is converted by GS into glutamine whereas one-third is transported into mitochondria and converted to alpha-ketoglutarate (Hertz and Zielke, 2004).

The prolongation of STC time course observed after GS inhibition reflects a delayed clearance of extracellular glutamate and to a potent diffusion of the transmitter at distant sites as demonstrated by a larger peri/extrasynaptic NMDA response elicited by HFS in MSO compared with saline injected animals. Moreover, the observations that low concentration of TBOA prolonged the decay time constant of both $S_{T C} C_{L F S}$ and NMDAR-EPSC $C_{L F S}$ support the relationship between STC time course on one hand, and the kinetic of the NMDA response on the other hand, and indicate that glutamate transporters in astrocytes limit NMDA receptors activation at a juvenile stage (see also Hanson et al., 2015). We cannot exclude that neuronal glutamate transporters could also play an important role in shaping the NMDA response, as demonstrated in the CA1 region of the hippocampus (Diamond, 2001; Scimemi et al., 2009) but this was not investigated in the present study. Here, pyramidal cells were recorded at $+40 \mathrm{mV}$ a condition, which is not favorable for glutamate transport by neuronal glutamate transporters.

It has been suggested that intracellular ionic composition influences the cycling or turnover rate of glutamate transporters. As mentioned by Huang and Bergles (2004) and by Wadiche et al. (2006), the turnover rate of glutamate transporters of the same identity can vary from a preparation to another. Thus, the turnover rate of GLT1 in hippocampal astrocytes measured in outside-out patch configuration is about $11 \mathrm{~ms}$ at $-90 \mathrm{mV}$ (Bergles and Jahr, 1998) whereas intracellular recording of transporter current in oocytes expressing GLT1 and that contain $10 \mathrm{~m} M$ glutamate and $10 \mathrm{~m} M \mathrm{Na}^{+}$showed that this rate was about $70 \mathrm{~ms}$ (Wadiche et al., 1995). It is therefore possible that GS inhibition through intracellular glutamate accumulation, and in presence of $\mathrm{Na}^{+}$, slow down the cycling rate of transporters and affects the capture efficiency i.e., the likelihood of glutamate to be translocated and released intracellularly as opposed to unbind extracellularly. Indeed, experimental data on the uncoupled anion transporter current and simulations suggest that before the final intracellular unbinding of glutamate and $\mathrm{Na}^{+}$, glutamate transporter seesaw between 2 states in which both ions are bind to the external face and to the internal face of the transporter, glutamate translocation forward and backward rates are almost equal for GLT1 (Bergles et al., 2002). In the presence of $\mathrm{Na}^{+}$and glutamate inside, the transporter has higher probability to keep bouncing between these 2 states delaying the intracellular unbinding of glutamate and $\mathrm{Na}^{+}$, the reorientation of the transporter to the outside by the intracellular $\mathrm{K}^{+}$ions and thus the possibility for the transporter to uptake another molecule of glutamate from the extracellular space. This mechanism could reduce the capacity of glutamate transporters near synaptic sites to rapidly uptake glutamate when released by HFS and favor diffusion of the transmitter to glutamate transporters at distant sites. This may explain the prolongation of $\mathrm{STC}_{\mathrm{HFS}}$ time course. Therefore, maintaining low glutamate concentration (and also $\mathrm{Na}^{+}$) in cytosol may be instrumental for astrocytes to efficiently clear glutamate released under certain circumstances of activation.

The actual resting concentration of glutamate in cortical astrocytes seems to range between 0.5 and $1 \mathrm{~m} M$ in rodent (Nedergaard et al., 2002; Zhou et al., 2014) and was estimated to be around $0.7 \mathrm{~m} M$ in human (Lebon et al., 2002). It is however not known how long it takes for glutamate after its transport in astrocytic process to reach back to this basal concentration. This may take longer time when GS is inhibited favoring glutamate accumulation. In physiological condition, the conversion of glutamate may be certainly fast enough since the decay time of $\mathrm{STC}_{\mathrm{HFS}}$ was close to that of $\mathrm{STC}_{\mathrm{LFS}}$ in astrocytes from saline injected rat during the different series of stimulation or in astrocytes recorded without glutamate in the patch pipette. However, we found that the ratio of the decay time constant of $\mathrm{STC}_{\mathrm{HFS}} / \mathrm{STC} \mathrm{C}_{\mathrm{LFS}}$ was $\sim 1.25$. This value differs from what was observed in the CA1 region of the hippocampus from juvenile rats, where Diamond and Jahr (2000) found a ratio of $\sim 1$. This suggests that neocortical astrocytic glutamate transporters close to synaptic sites would be less efficient to uptake glutamate released by HFS than those from the hippocampus. Interestingly, it was recently shown that astrocyte glutamate transporters mature later in the neocortex than in the hippocampus (Hanson et al., 2015). Immunofluorescence studies showed that GLT1 and GLAST are $\sim 40 \%$ less expressed in the neocortex than in the hippocampus from juvenile rats (Hanson et al., 2015). These authors provide also evidences that transporter current evoked by glutamate photolysis, decays slower in the neocortex than in the hippocampus until the third postnatal weeks of life. In keeping with this, the time course of STC recorded in the present study was also slower than the one previously reported in hippocampal astrocytes at the same developmental stage (Thomas et al., 2011). In addition, a study that has just been published while this article was revised showed that the efficiency of glutamate uptake in the adult mice neocortex was modulated by presynaptic activity but by a process that is independent of the amount of glutamate released. The clearance of glutamate is slowed when glutamate is released by burst of neuronal activity $>30 \mathrm{~Hz}$ and particularly by 10 
stimuli at $100 \mathrm{~Hz}$ (Armbruster et al., 2016). These observations, if this hold true in rat at juvenile stage, could also explain the ratio $>1$ of the decay time constant of $\mathrm{STC}_{\mathrm{HFS}} /$ $\mathrm{STC}_{\mathrm{LFS}}$ obtained here.

It has been shown in different preparations that the activity of GS is fundamental for synaptic transmission (Marx et al., 2015). This enzyme converts glutamate into glutamine, which is released by astrocytes and taken up by neurons where it is converted into glutamate by the phosphate activated glutaminase (Coulter and Eid, 2012; Marx et al., 2015). Our data show that synaptic transmission mediated by AMPA receptors are not impacted by the inactivation of GS. More precisely, the charge transfer of EPSC evoked by LFS and HFS as well as the ratio of $\mathrm{EPSC}_{\mathrm{HFS}} / \mathrm{EPSC}_{\mathrm{LFS}}$ were relatively constant with the iteration of the $100 \mathrm{~Hz}$ stimulation and not different from the results obtained from saline treated rats. In addition, the mean charge transfer of both STC $C_{\mathrm{LFS}}$ and $\mathrm{STC}_{\mathrm{HFS}}$ were not different in the two groups of rat. These data suggest that GS activity is not necessary to sustain glutamate synaptic transmission in the neocortex. These results apparently disagree the conclusion of Tani et al. (2010, 2014) about the requirement of glutamate/glutamine cycle to sustain glutamate synaptic transmission in neocortex. The most likely explanation for this discrepancy is the experimental procedure and the situation of high demand of glutamate resulting from persistent epileptiform activity (Tani et al., 2010) or from the protocol of stimulation used by Tani et al. (2014) i.e., iteration of intermittent stimulation at $20 \mathrm{~Hz}$ for $40 \mathrm{~s}$ separated by stimulation at $0.2 \mathrm{~Hz}$. Our procedure is certainly not sufficiently strong to deplete vesicles pools of glutamate as was the case in the experiments of Tani et al. (2014) and for which the synthesis of glutamate from glutamine may be important to replenish the pool of glutamate in presynaptic terminals. In our condition, the delay between 2 bursts of HFS and 2 series of stimulation were of $30 \mathrm{~s}$. This delay may allow expression of alternatives mechanism of recycling via glutamine i.e., other metabolic pathways and presynaptic uptake of glutamate via GLT-1 (Marcaggi and Attwell, 2004; Marx et al., 2015; Danbolt et al., 2016). We cannot however fully exclude in our situation that the residual amount of glutamine in slices from MSO treated rats could also help maintaining synaptic transmission.

The importance of GS for cortical network activity and brain development is highlighted by the deleterious effects of mutations in the human GLUL gene that encodes GS, leading to a strong inactivation of GS and associated with severe brain malformations, with seizures, and with early epileptic encephalopathy (Häberle et al., 2005, 2011). In rodent, mice lacking GS in astrocytes die rapidly after birth (He et al., 2010). Moreover, different studies have shown that the reactive astrocytes seen in a variety of pathological conditions including mesial temporal lobe epilepsy, do not express GS (Coulter and Eid, 2012; Eid et al., 2013). A defect in GS activity may have various consequences due to an increase in ammonia concentration in the brain and to the lack of glutamine synthesis leading to a reduction of GABAergic inhibition (He et al., 2010; Kelly et al., 2009; Liang et al., 2006; Ortinski et al., 2010), which may contribute to the generation of seizures. The delayed clearance and spillover of glutamate described in the present study, following a pattern of stimulation that could also happen during seizures, is likely to contribute to the maintenance of a hyperexcitable state. The possibility that this mechanism is actually operating in epilepsy will be investigated in future studies in the appropriate animal model and will help to clarify the electrophysiological consequences of a dysregulation of glutamate catabolism and homeostasis that is associated with some epileptic disorders.

\section{Acknowledgment}

Grant sponsors: INSERM, Aix-Marseille University, and by the Tunisian Ministry for Education and Research (Y.T.).

The authors would like to thank Christophe Melon at IBDML (Marseille) for the use of HPLC and his contribution in the analysis of amino acids content in slices. They are also grateful to Drs Paikan Marcaggi and Pierre Szepetowski for their helpful comments and criticism of the manuscript.

\section{References}

Armbruster M, Hanson E, Dulla CG. 2016. Glutamate clearance is locally modulated by presynaptic terminal activity in the cerebral cortex. J Neurosci 36:10404-10415.

Arnth-Jensen N, Jabaudon D, Scanziani M. 2002. Cooperation between independent hippocampal synapses is controlled by glutamate uptake. Nat Neurosci 5:325-331.

Asztely F, Erdemli G, Kullmann DM. 1997. Extrasynaptic glutamate spillover in the hippocampus: Dependence on temperature and the role of active glutamate uptake. Neuron 18:281-293.

Barbour B, Brew H, Attwell D. 1991. Electrogenic uptake of glutamate and aspartate into glial cells isolated from the salamander (Ambystoma) retina. J Physiol 436:169-193.

Barnett NL, Pow DV, Robinson SR. 2000. Inhibition of Müller cell glutamine synthetase rapidly impairs the retinal response to light. Glia 30:64-73.

Bergles DE, Diamond JS, Jahr CE. 1999. Clearance of glutamate inside the synapse and beyond. Curr Opin Neurobiol 9:293-298.

Bergles DE, Jahr CE. 1998. Glial contribution to glutamate uptake at Schaffer collateral-commissural synapses in the hippocampus. J Neurosci 18:77097716.

Bergles DE, Tzingounis AV, Jahr CE. 2002. Comparison of coupled and uncoupled currents during glutamate uptake by GLT-1 transporters. J Neurosci 22:10153-10162.

Brew H, Attwell D. 1987. Electrogenic glutamate uptake is a major current carrier in the membrane of axolotl retinal glial cells. Nature 327:707-709.

Brusilow SW, Koehler RC, Traystman RJ, Cooper AJL. 2010. Astrocyte glutamine synthetase:Importance in hyperammonemic syndromes and potential target for therapy. Neurotherapeutics 7:452-470. 
Cattani AA, Bonfardin VD, Represa A, Ben-Ari Y, Aniksztejn L. 2007. Generation of slow network oscillations in the developing rat hippocampus after blockade of glutamate uptake. J Neurophysiol 98:2324-2336.

Cavelier P, Attwell D. 2005. Tonic release of glutamate by a DIDS-sensitive mechanism in rat hippocampal slices. J Physiol 564:397-410.

Cavelier P, Hamann M, Rossi D, Mobbs P, Attwell D. 2005. Tonic excitation and inhibition of neurons: ambient transmitter sources and computational consequences. Prog Biophys Mol Biol 87:3-16.

Chatton JY, Marquet P, Magistretti PJ. 2000. A quantitative analysis ofLglutamate-regulated $\mathrm{Na}+$ dynamics in mouse cortical astrocytes: implications for cellular bioenergetics. Eur J Neurosci 12:3843-3853.

Cloix JF, Tahi Z, Martin B, Hévor T. 2010. Selection of two lines of mice based on latency to onset of methionine sulfoximine seizures. Epilepsia 51: 118-128.

Coulter DA, Eid T. 2012. Astrocytic regulation of glutamate homeostasis in epilepsy. Glia 60:1215-1226.

Danbolt NC. 2001. Glutamate uptake.2001. Prog Neurobiol 65:1-105.

Danbolt NC, Furness DN, Zhou Y. 2016. Neuronal vs glial glutamate uptake: resolving the conundrum. Neuroch Int 98:29-45.

Demarque M, Represa A, Becq H, Khalilov I, Ben-Ari Y, Aniksztejn L. 2002. Paracrine intercellular communication by a $\mathrm{Ca}^{2+}$ and SNARE-independent release of GABA and glutamate prior to synapse formation. Neuron 36:10511061.

Demarque M, Villeneuve N, Manent JB, Becq H, Represa A, Ben-Ari Y, Aniksztejn L. 2004. Glutamate transporters prevent the generation of seizures in the developing rat neocortex. J Neurosci 24:3289-3294.

Diamond JS. 2001. Neuronal glutamate transporters limit activation of NMDA receptors by neurotransmitter spillover on CA1 pyramidal cells. J Neurosci 21:8328-8338.

Diamond JS, Jahr CE. 2000. Synaptically released glutamate does not overwhelm transporters on hippocampal astrocytes during high-frequency stimulation. J Neurophysiol 83:2835-2843.

Eid T, Thomas MJ, Spencer DD, Rundén-Pran E, Lai JC, Malthankar GV, Kim JH, Danbolt NC, Ottersen OP, de Lanerolle NC. 2004. Loss of glutamine synthetase in the human epileptogenic hippocampus: Possible mechanism for raised extracellular glutamate in mesial temporal lobe epilepsy. Lancet 363:28-37.

Eid T, Ghosh A, Wang Y, Beckström H, Zaveri HP, Lee TS, Lai JC, Malthankar-Phatak GH, de Lanerolle NC. 2008. Recurrent seizures and brain pathology after inhibition of glutamine synthetase in the hippocampus in rats. Brain 131:2061-2070.

Eid T, Tu N, Lee TS, Lai JC. 2013. Regulation of astrocyte glutamine synthetase in epilepsy. Neurochem Int 63:670-681.

Grewer C, Rauen T. 2005. Electrogenic glutamate transporters in the CNS: Molecular mechanism, pre-steady-state kinetics, and their impact on synaptic signaling. J Membr Biol 203:1-20.

Häberle J, Görg B, Rutsch F, Schmidt E, Toutain A, Benoist JF, Gelot A, Suc AL, Höhne W, Schliess F, Häussinger D, Koch HG. 2005. Congenital glutamine deficiency with glutamine synthetase mutations. N Engl J Med 353: 1926-1933.

Häberle J, Shahbeck N, Ibrahim K, Hoffmann GF, Ben-Omran T. 2011. Natural course of glutamine synthetase deficiency in a 3 year old patient. Mol Genet Metab 103:89-91.

Hanson E, Armbruster M, Cantu D, Andresen L, Taylor A, Danbolt NC, Dulla CG. 2015. Astrocytic glutamate uptake is slow and does not limit neuronal NMDA receptor activation in the neonatal neocortex. Glia 63:1784-1796.

He Y, Hakvoort TB, Vermeulen JL, Labruyère WT,D, Waart DR, Van Der Hel WS, Ruijter JM, Uylings HB, Lamers WH. 2010. Glutamine synthetase deficiency in murine astrocytes results in neonatal death. Glia 58:741-754.

Hertz L, Zielke HR. 2004. Astrocytic control of glutamatergic activity: astrocytes as stars of the show. Trends Neurosci 27:735-743.
Herman MA, Jahr CE. 2007. Extracellular glutamate concentration in hippocampal slice. J Neurosci 27:9736-9741.

Huang YH, Bergles DE. 2004. Glutamate transporters bring competition to the synapse. Curr Opin Neurobiol 14:346-352.

Jabaudon D, Shimamoto K, Yasuda-Kamatani Y, Scanziani M, Gähwiler BH, Gerber U. 1999. Inhibition of uptake unmasks rapid extracellular turnover of glutamate of nonvesicular origin. Proc Natl Acad Sci U S A 96:8733-8738.

Kafitz KW, Meier SD, Stephan J, Rose CR. 2008. Developmental profile and properties of sulforhodamine 101-labeled glial cells in acute brain slices of rat hippocampus. J Neurosci Methods 169:84-92.

Kelly T, Kafitz KW, Roderigo C, Rose CR. 2009. Ammonium-evoked alterations in intracellular sodium and $\mathrm{pH}$ reduce glial glutamate transport activity. Glia 57:921-934.

Laake JH, Slyngstad TA, Haug FM, Ottersen OP. 1995. Glutamine from glial cells is essential for the maintenance of the nerve terminal pool of glutamate: Immunogold evidence from hippocampal slice cultures. J Neurochem 65:871-881.

Lebon V, Petersen KF, Cline GW, Shen J, Mason GF, Dufour S, Behar KL, Shulman GI, Rothman DL. 2002. Astroglial contribution to brain energy metabolism in humans revealed by $13 \mathrm{C}$ nuclear magnetic resonance spectroscopy: Elucidation of the dominant pathway for neurotransmitter glutamate repletion and measurement of astrocytic oxidative metabolism. J Neurosci 22:1523-1531.

Le Meur K, Galante M, Angulo MC, Audinat E. 2007. Tonic activation of NMDA receptors by ambient glutamate of non-synaptic origin in the rat hippocampus. J Physiol 580:373-383.

Liang SL, Carlson GC, Coulter DA. 2006. Dynamic regulation of synaptic GABA release by the glutamate-glutamine cycle in hippocampal area CA1. J Neurosci 26:8537-8548.

Maragakis NJ, Rothstein JD. 2004. Glutamate transporters: animal models to neurological disease. Neurobiol Dis 15:461-473.

Marcaggi P, Attwell D. 2004. Role of glial amino acid transporters in synaptic transmission and brain energetics. Glia 47:217-225.

Marx MC, Billups D, Billups B. 2015. Maintaining the presynaptic glutamate supply for excitatory neurotransmission. J Neurosci Res 93:1031-1044.

Melone M, Bellesi M, Conti F. 2009. Synaptic localization of GLT-1a in the rat somatic sensory cortex. Glia 57:108-117.

Milh M, Becq H, Villeneuve N, Ben-Ari Y, Aniksztejn L. 2007. Inhibition of glutamate transporters results in a "suppression-burst" pattern and partial seizures in the newborn rat. Epilepsia 48:169-174.

Molinari F, Cattani AA, Mdzomba JB, Aniksztejn L. 2012. Glutamate transporters control metabotropic glutamate receptors activation to prevent the genesis of paroxysmal burst in the developing hippocampus. Neuroscience 207:25-36.

Murphy-Royal C, Dupuis JP, Varela JA, Panatier A, Pinson B, Baufreton J, Groc L, Oliet SH. 2015. Surface diffusion of astrocytic glutamate transporters shapes synaptic transmission. Nat Neurosci 18:219-226.

Nedergaard M, Takano T, Hansen AJ. 2002. Beyond the role of glutamate as a neurotransmitter. Nat Rev Neurosci 3:748-755.

Ortinski PI, Dong J, Mungenast A, Yue C, Takano H, Watson DJ, Haydon PG, Coulter DA. 2010. Selective induction of astrocytic gliosis generates deficits in neuronal inhibition. Nat Neurosci 13:584-591.

Otis TS, Jahr CE. 1998. Anion currents and predicted glutamate flux through a neuronal glutamate transporter. J Neurosci 18:7099-7110.

Perez EL, Lauritzen F, Wang Y, Lee TS, Kang D, Zaveri HP, Chaudhry FA, Ottersen OP, Bergersen LH, Eid T. 2012. Evidence for astrocytes as a potential source of the glutamate excess in temporal lobe epilepsy. Neurobiol Dis 47:331-337.

Scimemi A, Tian H, Diamond JS. 2009. Neuronal transporters regulate glutamate clearance, NMDA receptor activation, and synaptic plasticity in the hippocampus. J Neurosci 29:14581-14595.

Sellinger OZ, Azcurra JM, Ohlsson WG. 1968. Methionine sulfoximine seizures. The dissociation of the convulsant and glutamine synthetase inhibitory effects. J Pharmacol Exp Ther 164:212-222. 
Sepkuty JP, Cohen AS, Eccles C, Rafiq A, Behar K, Ganel R, Coulter DA, Rothstein JD. 2002. A neuronal glutamate transporter contributes to neurotransmitter GABA synthesis and epilepsy. J Neurosci 22:6372-6379.

Takahashi M, Billups B, Rossi D, Sarantis M, Hamann M, Attwell D. 1997. The role of glutamate transporters in glutamate homeostasis in the brain. J Exp Biol 200:401-409.

Tanaka K, Watase K, Manabe T, Yamada K, Watanabe M, Takahashi K, Iwama H, Nishikawa T, Ichihara N, Kikuchi T, Okuyama S, Kawashima N, Hori S, Takimoto M, Wada K. 1997. Epilepsy and exacerbation of brain injury in mice lacking the glutamate transporter GLT-1. Science 276:1699-1702.

Tani H, Dulla CG, Farzampour Z, Taylor-Weiner A, Huguenard JR, Reimer RJ. 2014. A local glutamate-glutamine cycle sustains synaptic excitatory transmitter release. Neuron 81:888-900.

Tani H, Dulla CG, Huguenard JR, Reimer RJ. 2010. Glutamine is required to persistent epileptiform activity in disinhibited neocortical brain slice. J Neurosci 30:1288-1300.
Thomas CG, Tian H, Diamond JS. 2011. The relative roles of diffusion and uptake in clearing synaptically released glutamate change during early postnatal development. J Neurosci 31:4743-4754.

Tzingounis AV, Wadiche Jl. 2007. Glutamate transporters: Confining runaway excitation by shaping synaptic transmission. Nat Rev Neurosci 8:935-947.

Vandenberg RJ, Ryan RM. 2013. Mechanisms of glutamate transport. Physiol Rev 93:1621-1657.

Wadiche JI, Arriza JL, Amara SG, Kavanaugh MP. 1995. Kinetics of a human glutamate transporter. Neuron 14:1019-1027.

Wadiche JI, Tzingounis AV, Jahr CE. 2006. Intrinsic kinetics determine the time course of neuronal synaptic transporter currents. Proc Natl Acad Sci U S A 103:1083-1087.

Zhou Y, Wang X, Tzingounis AV, Danbolt NC, Larsson HP. 2014. EAAT2 (GLT-1; slc1a2) glutamate transporters reconstituted in liposomes argues against heteroexchange being substantially faster than net uptake. J Neurosci 34:13472-13485. 